\title{
Smålommens Gavia stellata häckningsframgång i artens svenska kärnområde
}

\author{
BÖRJE DAHLÉN \& MATS O. G. ERIKSSON
}

\begin{abstract}
We investigated the breeding success of a Red-throated Diver Gavia stellata population of approximately 70 pairs during ten seasons, $1991-2000$, in a $1820 \mathrm{~km}^{2}$ study area, dominated by coniferous forests and mires in Malung, Dalarna in Central Sweden. The majority of the pairs bred in tarns smaller than 1.0 ha and foraged in larger freshwater lakes or rivers up to a distance of $4.6 \mathrm{~km}$. Average breeding success was 0.76 "large" chicks per pair and year, with a declining trend over the study period accompanied by a decline in the proportion of broods with two "large" chicks. Breeding success was higher in seasons with an average early start of incubation and could be related to higher hatching success and survival of chicks. Predation during incubation was probably an important reason for breeding failures, and abandoning or change of breeding tarns were related to breeding failures. The annual variation
\end{abstract}

of the percentage of broods with two "large" chicks was synchronised between pairs foraging at different fishing lakes, which indicates the influence of some large-scale regional factors linked to the availability of food. Chick survival in two-chicks broods was significantly lower than in one-chick broods. The declining trend in breeding success is an incitement for future monitoring, and any link to impaired foraging conditions needs to be more closely addressed.

Börje Dahlén, Strandvägen 6, 78235 Malung; e-post: borje.dahlen@telia.com

Mats O. G. Eriksson, MK Natur- och Miljökonsult, Tommered 6483, 43792 Lindome;

e-post: mke.eriksson@swipnet.se

Received 1 October 2001, Accepted 23 February 2002, Editor: D. Hasselquist

Liksom övriga lomarter har smålommen Gavia stellata sedan några årtionden givits stor uppmärksamhet i fågelskyddsarbetet (t.ex. Lindberg 1968, 1971). Det anses allmänt att arten varit på tillbakagång sedan lång tid, åtminstone i södra Sverige (t.ex. Rosenius 1942, SOF 1990). Smålommen skiljer sig från de andra lomarterna genom att den ofta häckar vid fisktomma småvatten och hämtar bytesfisken till ungarna i större klarvattenssjöar eller i havet, på avstånd upp till närmare 10 km från häckningsplatsen. I problembilden ingår bland annat störningar och biotopförändringar vid häckningstjärnarna (t.ex. dikning), utglesade fiskbestånd i fiskesjöar påverkade av försurning samt risken för en ökad exponering för kvicksilver genom födointaget (t.ex. Eriksson m.fl. 1988, 1992).

En stor del av det svenska beståndet häckar inom ett förhållandevis begränsat område i landets mellersta delar. I Dalarna, Värmland och Västmanland finns uppskattningsvis 370-440 par, eller ungefär en tredjedel av landets totala bestånd på 1200-1400 par, enligt bedömningar under 1990-talet (Eriksson \& Lindberg 1998). I samband med de rikstäckande inventeringarna av fågelfaunan på landets myrar under 1970- och 1980-talen uppskattades tätheten av det myrhäckande beståndet av smålom i denna del av landet till 11 par/100 km² myrmark, jämfört med 6 par/100 km² myrmark i södra Norrland, 2 par/100 $\mathrm{km}^{2}$ myrmark i norra Norrland och mindre än 1 par/ $100 \mathrm{~km}^{2}$ myrmarki Götaland (Arvidsson m.fl. 1992). Man bedömde att ungefär $70 \%$ av landets smålomspar häckade i myrmiljöer.

I den här uppsatsen behandlar vi olika aspekter av smålommens häckningsframgång under tioårsperioden 1991-2000 i ett barrskogs- och myrområde i västra Dalarna, inom smålommens svenska kärnområde. Vi hoppas att våra resultat kan vara till viss vägledning för det framtida fågelskyddsarbetet avseende smålommen i Sverige. 


\section{Material och metoder}

\section{Undersökningsområdet}

Undersökningen omfattar ett $1820 \mathrm{~km}^{2}$ stort barrskogs- och myrområde i Malungs kommun $\left(60^{\circ} 41^{\prime}\right.$ $\mathrm{N}, 13^{\circ} 43^{\prime} \mathrm{O}$ ) i Dalarna (Figur 1). Inom området finns ungefär 680 tjärnar med en areal upp till 8 ha och vi bedömer att cirka 70 smålomspar häckar i området, svarande mot en täthet av 3-4 par/100 km². Vårt material omfattar 95 tjärnar, där häckning fastställts

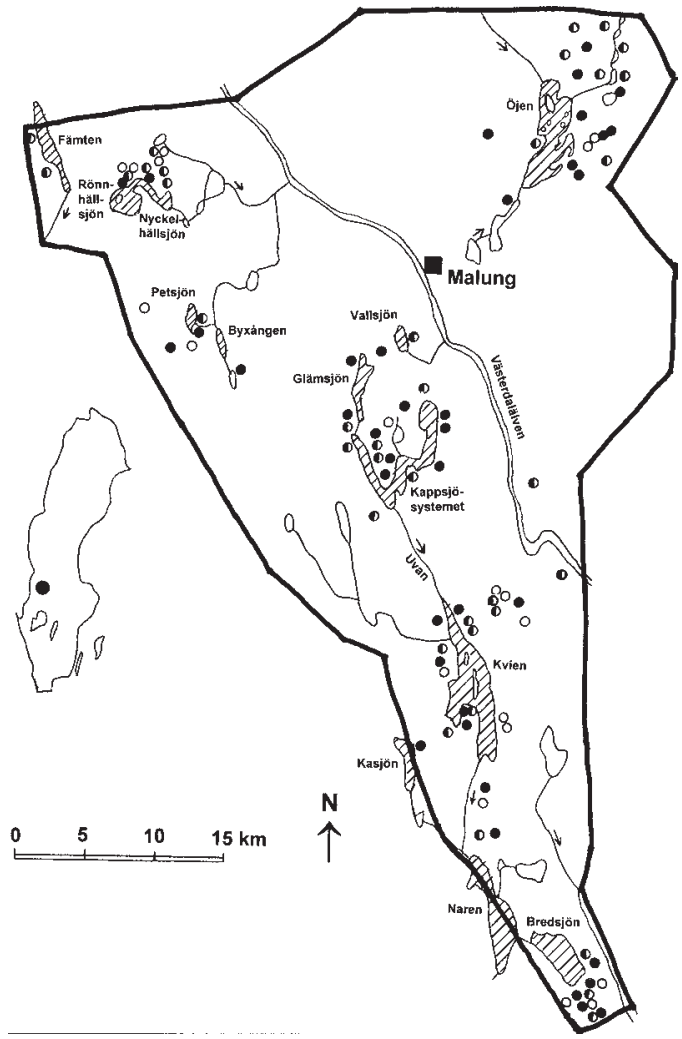

Figur 1. Karta över undersökningsområdet. De viktigaste fiskesjöarna är streckmarkerade. Helfyllda cirklar = häckningstjärnar undersökta minst 5 år och med häckning mer än $75 \%$ av åren, halvfyllda cirklar = häckningstjärnar undersökta minst 5 år och med häckning 25-75\% av åren, ofyllda cirklar = häckningstjärnar undersökta minst 5 år och med häckning mindre än $25 \%$ av åren.

Map over the study area. The most important foraging lakes are-marked with slanting lines. Filled circles $=$ breeding tarns investigated at least 5 years and where breeding occurred in more than $75 \%$ of the years, half-filled circles $=$ breeding tarns investigated at least 5 years and where breeding occurred in more $25-75 \%$ of the years, open circles = breeding tarns investigated at least 5 years and where breeding occurred in less than $25 \%$ of the years. under ett eller (i de flesta fall) flera år under perioden 1991-2000. Smålommarna fiskar i större, näringsfattiga sjöar och vattendrag i området. Flera av fiskesjöarna är försurningspåverkade och föremål för fortlöpande kalkningsinsatser.

\section{Väderförhållanden}

Vi har använt oss av uppgifter om månadsmedelvärden för temperatur och totalnederbörd vid SMHI:s mätstation vid Malung (uppgifterna från SMHI:s månatliga tidskrift "Väder och Vatten").

Procent bebodda häckningstjärnar, ungproduktion och häckningsframgång

Vi har använt följande häckningsindicier.

Stationärt par. Par i häckningsmiljö under häckningstid. Minst två observationer med minst två veckors mellanrum skall ha gjorts under samma säsong.

Häckande par. Häckningsindicium i form av observation av parning, bo, ägg, ruvande fågel och/ eller ungar föreligger.

Lyckad häckning. Häckning som resulterat i minst en "stor" (minst halvvuxen) unge.

Omhäckning. Vi har bedömt att en omhäckning har ägt rum bara i de fall när vi kunnat fastställa att det första häckningsförsöket misslyckats. Dettainnebär att enstaka häckningar som upptäckts förhållandevis sent under häckningssäsongen felaktigt kan ha klassificerats som "första"-häckningar.

Vi har använt oss av följande parametrar för bedömning av häckningsresultat (primärdata redovisas i Appendix 1).

Procentandelen tjärnar med häckning $i$ relation till antalet undersökta tjärnar. För att få ett mått på hur tjärnarna nyttjats av häckande smålommar (med "antalet undersökta tjärnar" avser vi det antal tjärnar som inventerats det aktuella året, inom ramen för de 95 tjärnar som undersökningen totalt omfattar).

Antal ägg. För att undvika att störa ruvande fåglar har vi inte konsekvent undersökt antalet ägg, utan detta har noterats bara i de fall då den ruvande fågeln inte legat på boet i samband med besök vid tjärnen.

Ungproduktion. Har beräknats som medelantalet "stora" ungar per häckande par. I beräkningsunderlaget har vi uteslutit häckningar som inte har följts upp till att ungarna blivit "stora", samt häckningar som fastställts först genom upptäckt av kläckta ungar, utan föregående notering av parning, bo, ägg eller ruvning. Med denna begränsning blir antalet par som ligger till grund för beräkningarna för de flesta 
år lägre än det verkliga antalet häckande par, och underlaget skiljer sig också något från vad som rapporterats tidigare från undersökningsområdet (t.ex. Dahlén 1997). Vi har parallellt beräknat medelantalet "stora" ungar per stationärt par, i första hand för att använda dessa siffror för bedömningar av andelen stationära men icke-häckande par (se nedan). Bland "stationära par" inräknas även enstaka par som hållits under bevakning under hela häckningsperioden och där ungar producerats, men där häckningen inte kunnat fastställas genom observation av parning, bo, ägg och/eller ruvande fågel tidigare under samma häckningssäsong.

Procentandelen lyckade häckningarmed två "sto$r a$ ” ungar. För att få ett mått på hur häckningsmiljön fungerat som "barnkammare" och uppväxtmiljö för ungarna. I dessa beräkningar har vi även tagit med häckningar som inte upptäckts förän efter att ungarna kläckts.

Häckningsframgången. Denna har beräknats med den s.k. Mayfield-metoden (Mayfield 1961, 1975, Johnson 1979, Beintema 1996). Den bygger på att häckningsframgången relateras till den totala tidsperiod (=antalet exponeringsdagar) som paren har hållits under observation. Vi har delat upp analysen i en beräkning av kläckningsframgången, d.v.s. sannolikheten för att en påbörjad ruvning leder fram till kläckning av minst en unge, och sannolikheten för att minst en unge överlever från kläckning till flygg ålder. Metoden ger i regel en bättre precision än traditionella beräkningar av procentandelen lyckade häckningar, och den underlättar jämförelser mellan olika undersökningar med fler än en orsak till att häckningar misslyckas (Beintema 1992). Primärdata redovisas i Appendix 2. Antalet exponeringsdagar under en och samma häckningssäsong var emellertid genomgående lägre än den rekommendation på ett minimum av 2000 exponeringsdagar som gäller för en verkligt god precision i beräkningarna (Beintema 1996). Vi har även jämfört sannolikheten för den individuella överlevnaden av ungar till flygg ålder i kullar med en respektive två ungar med Mayfield-metoden (primärdata i Appendix 3).

Procentandelen stationära par som häckat. Hos storlommen Gavia arctica förekommer det att stationära par kan upprätthålla ett revir men avstå från häckningen enstaka år (Lehtonen 1970, Götmark m.fl. 1989). Men det är oklart i vilken utsträckning detta förekommer hos smålommen. Smålomsparen kan vid inventeringarna ha bedömts som stationära par av minst två skäl; att det verkligen rört sig om ett stationärt par som inte häckat eller att häckning har skett men inte kunnat fastställas enligt de kriterier vi har använts oss av. Under antagandet att observationerna av "stora" ungar i relation till stationära respektive häckande par är lika representativa för det undersökta smålomsbeståndet, har vi beräknat procentandelen häckande par genom kvoten mellan medelantalet "stora" ungar per stationärt par och häckande par (medelantalet "stora" ungar per stationärt par kan ju beräknas som produkten av proportionen häckande par multiplicerat med medelantalet "stora" ungar per häckande par).

\section{Tidpunkt för ruvningsstart}

Tidpunkten för ruvningsstart har beräknats med Mayfield-metoden. Vi har bedömt att ruvningen påbörjats dagen mittemellan två observationer (Beintema 1996 för detaljer). När två händelser inträffat mellan två besök (t.ex. att en "första"-häckning har avbrutits och en omhäckning påbörjats) har vi delat in tidsperioden mellan besöken $i$ tre lika långa intervallen $( \pm 1$ dag om antalet dagar inte varit jämnt delbart med tre).

\section{Boets storlek och placering samt byte av boplats}

1991-1997 gjordes följande noteringar för flertalet bon.

Boets storlek. Största och minsta innerdiameter av bobalen mättes. Mätningarna är behäftade med en osäkerhet beroende på boets utformning, som kan variera från en enkel nedlegad grop på marken med ytterst lite bomaterial till ett uppbyggd bo av sammanpressade växtdelar.

Avstånd från bo till vatten. Mättes från innerkanten av boet till vattenbrynet utefter den "stig" som smålommarna nyttjat.

Avstånd från häckningsö till land (fast mark).

Alla mätningar av bon samt bedömningar av lämpliga boöar har gjorts av en och samma person (Börje Dahlén).

Vi har bedömt att ett byte av boplats vid samma tjärn har skett om fåglarna byggde ett nytt rede, även om detta låg "kant i kant" med ett tidigare använt bo. För boplatser belägna på häckningsöar har i regel krävts ett besök på ön, för att bedöma om ett byte av boplats har skett, t.ex. från ett år till nästa.

\section{Egenskaper hos häckningstjärnarna}

För de olika häckningstjärnarna har vi undersökt följande egenskaper (primärdata redovisas i Appendix 4).

Attraktiviteten för häckande smålommar. Denna 
har beräknats genom procentandelen år med häckning i relation till alla år då tjärnen inventerats.

Den genomsnittliga ungproduktionen i varje tjärn. Har beräknats genom medelantalet"stora" ungar per år. Inte i något fall har fler än ett häckande par noterats i varje tjärn.

Tjärnarnas attraktivitet och deras genomsnittliga ungproduktion har relaterats till följande egenskaper:

Areal. I tidigare undersökningar har man noterat att små tjärnar $(<1$ ha) varit mer attraktiva eller haft en högre kläckningsframgång (t.ex. på Shetlandsöarna; Gomersall 1986, Okill \& Wanless 1990). Samtidigt får inte tjärnarna vara så små att start och landning försvåras (Norberg \& Norberg 1971).

Avstånd till väg. Vi har använt detta mått som en indikator på störningar från besökande människor.

Avstånd till fiskevatten. Man har tidigare antagit att transport av bytesfisk från fiskevattnen till häckningstjärnarna är så energikrävande att avståndet sätter en övre gräns för valet av häckningssjöar och kanske även påverkar häckningsresultatet (t.ex. Eberl \& Picman 1993, Eriksson \& Johansson 1997).

Förekomst av lämpliga boöar. Bolägen på myröar och -holmar kan antas vara mindre sårbara för predation eller störningar från besökande människor (t.ex. Lokki \& Eklöf 1984). Under smålommens tillbakagång i sydvästra Sverige under mitten av 1900-talet övergavs tjärnar utan lämpliga häckningsöar i större utsträckning än tjärnar med småöar (Eriksson m.fl. 1988).

Genomströmmande vatten. Vi jämförde smålommens nyttjande och häckningsframgång i tjärnar med respektive utan väldefinierade tillflöden och utlopp. Detta mot bakgrund av att vattenståndet, t.ex. i samband med regn, kan tänkas variera på olika sätt för tjärnar med tydliga jämfört med mer diffusa utlopp (t.ex. via myrmarker).

\section{Jämförelser mellan fiskevatten}

Vi undersökte om eventuella skillnader i häckningsframgången kunde relateras till förhållanden i fiskevattnen. För sex fiskesjöar som nyttjades av minst fem smålomspar jämfördes den genomsnittliga procentandelen bebodda tjärnar, medelantalet "stora" ungar per par och år, samt den genomsnittliga procentandelen ungkullar med två "stora" ungar för de par som förmodats (och i flertalet fall fastställts) fiska i sjön.

\section{Resultat och diskussion}

\section{Inventerade tjärnar och par}

De flesta av de ungefär 680 tjärnarna i området har besökts minst en gång under undersökningsperioden, och 130-150 tjärnar har besökts varje år. Urvalet av tjärnar för fältbesök gjordes efter bedömningar från kartstudier av vilka tjärnar som verkade mest lämpliga för smålom. Vår undersökning omfattar 95 av dessa tjärnar, d.v.s. de där häckning av smålom har fastställts under minst ett år under perioden 1991-2000. Bland dessa har mellan 66 och 92 tjärnar besökts varje år. 70 tjärnar $(74 \%)$ besöktes under nio eller tio år, och $91(96 \%)$ av dem besöktes under minst fem år (Tabell 1). Inte i något fall noterades mer än ett stationärt eller häckande par i någon tjärn.

Antalet inventerade stationära par varierade från 42 par 1991 till 74 par 1999 och ökade signifikant under perioden 1991-2000 $\left(\right.$ Spearman $_{\mathrm{s}}=0,73, \mathrm{n}=10$ år, $0,01<\mathrm{P}<0,025$, data från Appendix 1). Vi bedömer att det ökade antalet är en kombinerad effekt av effektivare fältarbete och en verklig ökning av beståndets storlek.

Stationära eller häckande smålomspar uppträdde i ungefär två tredjedelar av de undersökta tjärnarna, sett som ett genomsnitt över hela undersökningsperioden. Procentandelen bebodda tjärnar ökade fram till 1999 (Figur 2, Spearman $r_{s}=0,93$ resp. 0,80 för andelen tjärnar med stationära resp. häckande par, $\mathrm{n}=9$ år, $\mathrm{P}<0,01$ ) vilket antyder en tillväxt av beståndets storlek. Därefter bröts emellertid trenden (tillfälligt?) då den lägsta andelen bodda tjärnar under hela undersökningsperioden noterades 2000. Räknat över hela tioårsperioden finns således ingen

Tabell 1. Antal tjärnar som undersökts olika antal år. Number of tarns surveyed different number of years.

\begin{tabular}{lcr}
\hline $\begin{array}{l}\text { Ar } \\
\text { Years }\end{array}$ & $\begin{array}{l}\text { Antal } \\
\text { Number }\end{array}$ & $\%$ \\
\hline 10 & 58 & 61 \\
9 & 14 & 15 \\
8 & 6 & 6 \\
7 & 7 & 7 \\
6 & 1 & 1 \\
5 & 5 & 5 \\
4 & 2 & 2 \\
3 & 1 & 1 \\
2 & 1 & 1 \\
1 & 0 & 0 \\
\hline Totalt & 95 & \\
\hline
\end{tabular}




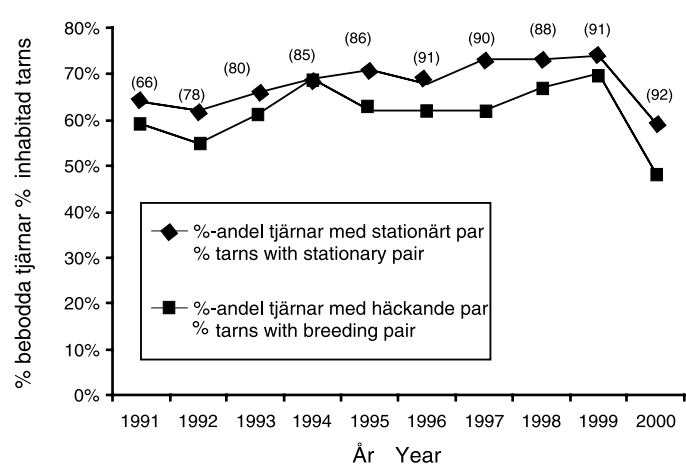

Figur 2. Procentandelen bebodda tjärnar (primärdata i Appendix 1). Antalet undersökta tjärnar inom parantes.

Percentage of inhabited tarns, calculated from primary data presented in Appendix 1. Number of investigated tarns in parentheses.

Tabell 2. Datum för ruvningsstart. $\mathrm{N}=$ antal kullar. Date for start of incubation. $N=$ number of clutches. statistiskt signifikant trend. Framtida uppföljningar får visa om den låga andelen bebodda tjärnar 2000 indikerade ett trendbrott.

Procentandelen tjärnar med häckande par tenderade (paradoxalt nog?) att vara lägre under år med hög medeltemperatur i maj (Spearman $r_{s}=-0,46$, $\mathrm{N}=10$ år, $0,05<\mathrm{P}<0,10)$, medan nederbörden verkar sakna betydelse (Spearman $r_{s}=-0,24, N=10$ år, ej sign.). Det fanns ingen tendens till att vare sig temperatur eller nederbörd under juni påverkade procentandelen tjärnar med häckning (Spearman $r_{s}$ = 0,04 resp. 0,13 för motsvarande jämförelser).

\section{Tidpunkt för häckningens början}

Ruvningsstarten för första-häckningar var utspridd över en period på ungefär en och en halv månad, från mitten av maj till slutet av juni. Omhäckningar påbörjades från början av juni till mitten av juli (Tabell 2). Mot bakgrund av en genomsnittlig ruvningstid på

\begin{tabular}{|c|c|c|c|c|c|c|c|c|c|}
\hline År & $\mathrm{N}$ & $\begin{array}{l}\text { Median- } \\
\text { datum }\end{array}$ & & Numbe & $\begin{array}{l}\text { tal påb } \\
\text { of initi }\end{array}$ & $\begin{array}{l}\text { de häck } \\
\text { breedin }\end{array}$ & $\begin{array}{l}\text { gar, } \\
\text { tempts }\end{array}$ & & \\
\hline Year & $N$ & $\begin{array}{l}\text { Median } \\
\text { date }\end{array}$ & $\begin{array}{l}\text { 11-20 } \\
\text { maj }\end{array}$ & $\begin{array}{l}21-31 \\
\text { maj }\end{array}$ & $\begin{array}{l}1-10 \\
\text { juni }\end{array}$ & $\begin{array}{l}11-20 \\
\text { juni }\end{array}$ & $\begin{array}{l}21-30 \\
\text { juni }\end{array}$ & $\begin{array}{l}1-10 \\
\text { juli }\end{array}$ & $\begin{array}{l}11-20 \\
\text { juli }\end{array}$ \\
\hline
\end{tabular}

"Första"-häckningar

$1^{\text {st }}$ clutches

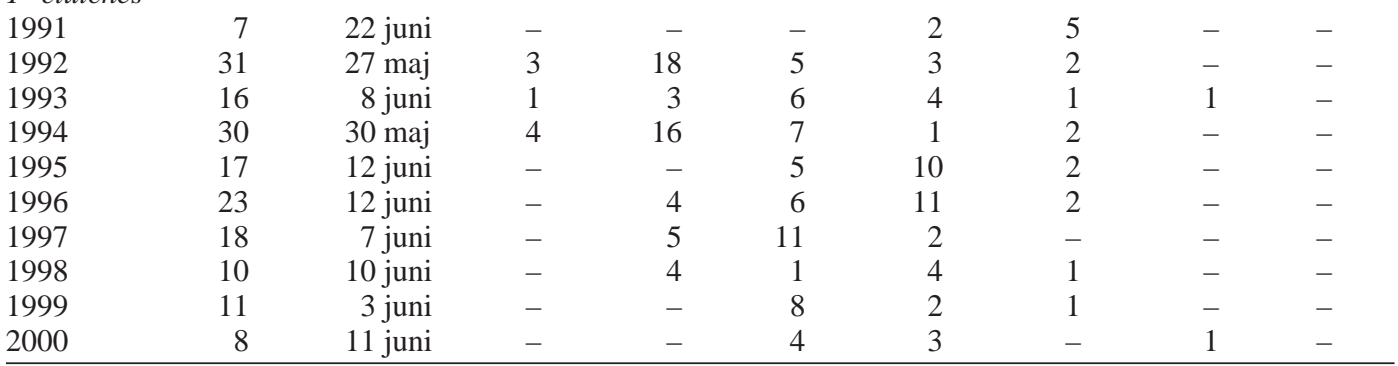

Omhäckningar

Replacements

\begin{tabular}{llllllllll}
\hline 1991 & 2 & 20 juni & - & - & - & 2 & - & - & - \\
1992 & 6 & 18 juni & - & - & 1 & 2 & 3 & - & - \\
1993 & 1 & 19 juni & - & - & - & 1 & - & - & - \\
1994 & 4 & 13 juni & - & - & 2 & 1 & 1 & - & - \\
1995 & 3 & 3 juli & - & - & - & 1 & - & 1 & 1 \\
1996 & 3 & 24 juni & - & - & - & - & 3 & - & - \\
1997 & 5 & 26 juni & - & - & 1 & 1 & 1 & 2 & - \\
1998 & 3 & 18 juni & - & - & - & 3 & - & - & - \\
1999 & 1 & 19 juni & - & - & - & 1 & - & - & - \\
2000 & 1 & 2 juli & - & - & - & - & - & 1 & - \\
\hline
\end{tabular}


28 dagar och att ungarna i regel blir flygga 38 dagar senare (Gomersall 1986), kan ruvande smålommar påträffas från mitten av maj till början av augusti, och icke flygga ungar från mitten av juni till mitten av september. Ruvningsstarten för ungefär hälften av "första"-häckningarna var emellertid koncentrerad till en begränsad tiodagarsperiod, men när denna period inträffade varierade mellan åren från slutet av maj till mitten av juni (Tabell 2). Det fanns ingen tendens till att andelen tjärnar med häckande par varierade mellan åren med hänsyn till mediandatum för ruvningsstart (Spearman $r_{s}=-0,26, N=10$ år, ej sign.). Möjligen fanns ett (ej statistiskt signifikant) samband mellan tidig ruvningsstart och hög temperatur i maj (Spearman $\mathrm{r}_{\mathrm{s}}=-0,44, \mathrm{~N}=10$ år, $0,05<\mathrm{P}<0,10)$, medan nederbörden torde sakna betydelse (Spearman $r_{s}=0,24, N=10$ år, ej sign.).

\section{Äggkullstorlek, ungproduktion och häckningsfram- gång}

Antalet ägg har fastställts för totalt 54 kullar (antalet undersökta kullar per år 2-12). Tolv av kullarna (22\%) innehöll ett ägg och resterande 42 kullar (78\%) två ägg, svarande mot ett medelvärde på 1,78 ägg per kull. Resultatet är helt i linje med tidigare undersökning både i Sverige och Skottland som visar att majoriteten av alla smålomspar lägger två ägg (t.ex. Cramp \& Simmons 1977, Borgström 1993).

Den genomsnittliga ungproduktionen var 0,76 "stora" ungar per par och år, med en tendens till försämring under undersökningsperioden (Spearman $r_{s}=0,55,0,05<P<0,10$; Figur 3). Ungproduktionen låg i nivå med vad som noterades för ett större område i mellersta Sverige inom ramen för de inventeringar som samordnats av Projekt LOM under perioden 1994-99 (0,71 "stora" ungar per par och

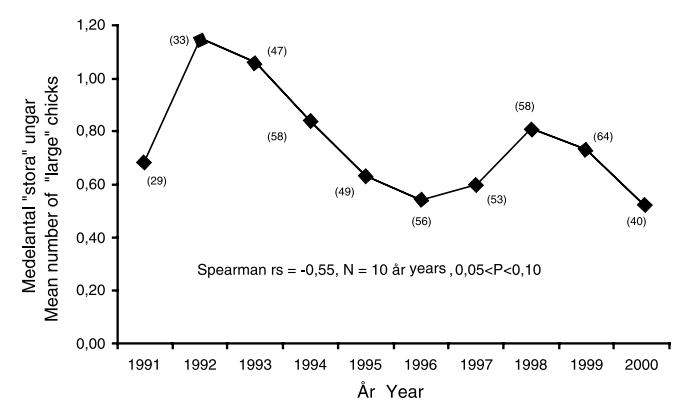

Figur 3. Medelantalet "stora" ungar per par. Data från Appendix 1. Antalet undersökta par inom parantes.

Mean number of "large" chicks per pair. Data from Appendix 1. Number of investigated pairs in parentheses. år), men lägre än vad som noterades under samma period för smålommar häckande i sydvästra Sverige (0,91 "stora" ungar per par och år) och i Norrland (1,05 resp. 0,97 "stora" ungar per par och år för insjö- resp. havsfiskande par; Eriksson \& Lindberg 2000a). Den negativa trenden i ungproduktionen torde i första hand vara kopplad till att andelen lyckade häckningar med två "stora" ungar minskade under undersökningsperioden (Figur 8), medan tidstrenden när det gäller kläckningsframgången inte var lika tydlig (Spearman $r_{s}=-0,37, N=10$ år, ej sign., primärdata från Appendix 1).

Med referens till några andra undersökningar bedömer vi att den genomsnittliga ungproduktionen 1991-2000 varit tillräcklig för att bibehålla beståndets storlek på en oförändrad nivå. På Orkneyöarna var den genomsnittliga ungproduktionen 0,70 "stora" ungar per par och år under perioden 1973-80 (13 undersökta par, Booth 1982), medan den på Shetlandsöarna var betydligt lägre, 0,44 "stora" ungar per par och år 1981-83 (91-100 par, Gomersall 1986). Från början av 1980-talet och fram till 1994 minskade smålomsbeståndets storlek på Shetlandsöarna från omkring 700 par till 390 par medan antalet par på Orkneyöarna var oförändrat, 90-100 par (Gibbons m.fl. 1994). Hos ett smålomsbestånd under tillväxt i södra Finland 1979-82 var ungproduktionen 1,15 "stora" ungar per par (17-32 par, Lokki \& Eklöf 1984).

Andelen häckande par i relation till totala antalet stationära par varierade från $84 \%$ till $100 \%$ (beräknat på basis av rådata från Appendix 1), och det fanns ingen tydlig trend över undersökningsperioden (Spearman $r_{s}=-0,31, N=10$ år, ej sign.). Däremot fanns en samvariation mellan andelen häckande par och ungproduktionen (Spearman $r_{s}=0,52, N=10$ år, $0,05<\mathrm{P}<0,10)$, vilket antyder att någon gemensam bakomliggande faktor kan ha påverkat både de stationära parens benägenhet att påbörja en häckning och ungproduktionen. Det fanns inget samband mellan procentandelen tjärnar med häckande par och ungproduktionen (Spearman $r_{s}=0,14, N=10$ år, ej sign., primärdata från Appendix 1).

Det fanns ett statistiskt signifikant samband för att ungproduktionen var högre under år med tidig ruvningsstart (Figur 4). Till skillnad från vad som noterats på Shetlandsöarna (Gomersall 1986), fann vi däremot ingen tendens till en lägre kläckningsframgång bland sent påbörjade kullar. Mediandatum för ruvningsstart av "första"-kullar skiljde sig inte mellan kläckta och icke kläckta kullar under samma häckningssäsong (Tabell 3, Wilcoxons parvisa rangtest, $\mathrm{P}=0,50$, tvåsidigt, ej sign.). 
Tabell 3. Mediandatum för ruvningsstart. Jämförelse mellan antal kläckta och icke kläckta kullar. $\mathrm{N}=$ antal kullar.

Median date for start of incubation. Comparison between hatched and non-hatched clutches. $N=$ number of clutches.

\begin{tabular}{|c|c|c|c|c|}
\hline \multirow[b]{2}{*}{$\begin{array}{l}\text { År } \\
\text { Year }\end{array}$} & \multicolumn{2}{|c|}{$\begin{array}{l}\text { Kläckta } \\
\text { Hatched }\end{array}$} & \multicolumn{2}{|c|}{$\begin{array}{l}\text { Icke kläckta } \\
\text { Not hatched }\end{array}$} \\
\hline & $\mathrm{N}$ & $\begin{array}{l}\text { Median } \\
\text { Median }\end{array}$ & $\mathrm{N}$ & $\begin{array}{l}\text { Median } \\
\text { Median }\end{array}$ \\
\hline 1991 & 4 & 16 juni & 3 & 22 juni \\
\hline 1992 & 23 & 27 maj & 8 & 23 maj \\
\hline 1993 & 12 & 9 juni & 4 & 5 juni \\
\hline 1994 & 17 & $30 \mathrm{maj}$ & 13 & 30 maj \\
\hline 1995 & 9 & 13 juni & 8 & 11 juni \\
\hline 1996 & 10 & 15 juni & 13 & 12 juni \\
\hline 1997 & 8 & 9 juni & 10 & 4 juni \\
\hline 1998 & 6 & 1 juni & 5 & 18 juni \\
\hline 1999 & 7 & 3 juni & 4 & 10 juni \\
\hline 2000 & 5 & 8 juni & 3 & 13 juni \\
\hline $\begin{array}{l}\text { Medel } \\
\text { Mean }\end{array}$ & & 7 juni & & 9 juni \\
\hline
\end{tabular}

I genomsnitt kläcktes minst ett ägg i $63 \%$ av alla ruvade äggkullar, och i $91 \%$ av alla kläckta kullar överlevde åtminstone en unge till "stor" (halvflyggflygg) ålder (beräknat enligt Mayfield-metoden, rådata i Appendix 1 och 2). Ungproduktionen var tydligt kopplad till kläckningsframgången (Figur 5). Sammantaget lyckades $58 \%$ av alla påbörjade häckningar, i den meningen att minst en "stor" unge producerats och räknat som ett genomsnitt över undersökningsperioden. Procenttalen för andelen lyckade häckningar, beräknade på traditionellt sätt, var av samma storleksordning (om än inte exakt desamma) som resultaten av Mayfield-analysen (jämförelse mellan Tabell 9 och Appendix 2).

Det fanns ett statistiskt signifikant samband mellan högre ungproduktionen och såväl varmt väder som låg nederbörd under maj (Figur 6 och 7). Likaså var kläckningsframgången, beräknad med Mayfieldmetoden för de olika åren, kopplad till både varmt väder och lite regn under maj (Spearman $r_{s}=0,62$ resp. - $-0,63$ för jämförelser mellan dygnsmedeltemperaturen resp. nederbörden i maj och kläckningsframgången, $\mathrm{N}=10$ år, $0,025<\mathrm{P}<0,05$, data från Appendix 1). Men det fanns också ett samband mellan mediandatum för ruvningsstart och ungproduktionen (Figur 4) och möjligen även ett samband mellan temperaturen i maj och mediandatum för

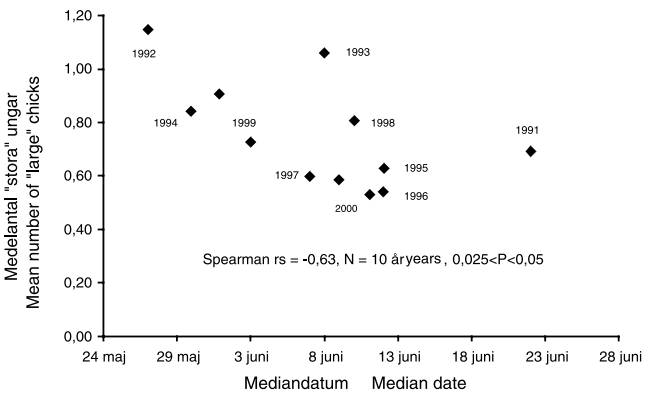

Figur 4. Medelantal "stora" ungar per par i relation till mediandatum för ruvningsstart av förstakullar. Data från Appendix 1 och Tabell 2.

Mean number of large chicks per pair in relation to the median date for start of incubation of first clutches. Data from Appendix 1 and Table 1 .

ruvningsstart. Slutsatsen att bra väder i maj leder till tidig ruvningsstart såväl som god kläckningsframgång ligger därför nära till hands, men man bör inte utesluta möjligheten att även andra faktorer kan ha medverkat till en bättre ungproduktion under år med tidig ruvningsstart. Däremot fanns ingen tendens till samband mellan medeltemperaturen i juni och ungproduktionen (Spearman $\mathrm{r}_{\mathrm{s}}=-0,10, \mathrm{~N}=10$ år, ej sign.), medan en negativ effekt av hög nederbörd inte kan uteslutas (Spearman $r_{s}=-0,41, N=10$ år, ej sign.).

\section{Omhäckningar}

I genomsnitt följdes $15 \%$ av alla första-häckningar som misslyckats under ruvningen av en omhäckning. Andelen omhäckningar varierade dock mar-

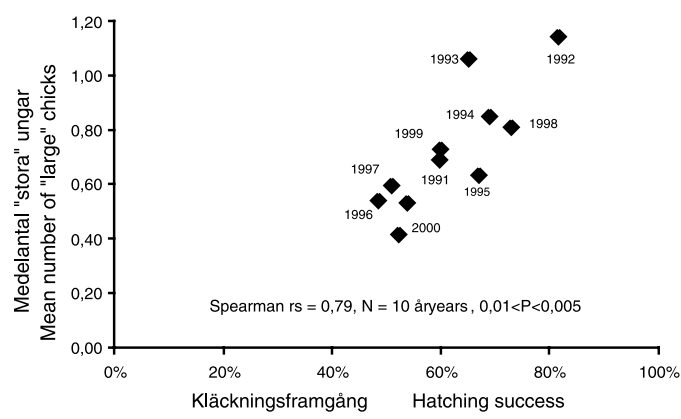

Figur 5. Medelantal "stora" ungar per par i relation till kläckningsframgången, beräknad enligt Mayfield-metoden (primärdata i Appendix 1 och 2).

Mean number of "large" chicks per pair in relation to hatching success, calculated with the Mayfield method (primary data in Appendices 1 and 2). 


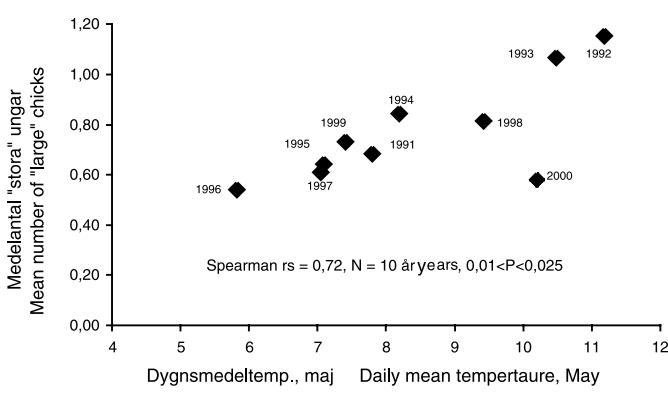

Figur 6. Ungproduktionen i relation till dygnsmedeltemperaturen under maj (primärdata från Appendix 1).

Production of young in relation to daily mean temperature in May (primary data from Appendix 1)

kant mellan åren, från 4\% år 1998 till 50\% år 1992 (data från Appendix 1). Det fanns ingen tendens till samband mellan andelen omhäckningar och mediandatum för ruvningsstart för "första"-häckningarna (Spearman $r_{s}=-0,30, N=10$ år, ej sign., data från Appendix 1 och Tabell 2).

Den genomsnittliga ungproduktionen var lägre bland omhäckningar jämfört med "första"-kullar, 0,56 resp. 0,73 "stora" ungar per par och år, men skillnaden var inte statistiskt signifikant (Wilcoxons parvisa rangstest: $\mathrm{P}=0,27$, tvåsidigt, $\mathrm{N}=10$ år). Samma resultat erhölls på Shetlandsöarna 1981-83 (Gomersall 1986), men i den undersökningen tolkades detta som en effekt av en allmänt lägre häckningsframgång bland sent påbörjade häckningar. Som tidigare nämnts, har vi emellertid inte funnit någon sådan tendens i vårt material, så vi vill inte utesluta möjligheten att omhäckningar generellt är mindre framgångsrika, kanske en effekt av ökade reproduktionskostnader för par som påbörjat två kullar samma säsong. Det fanns inte något påtagligt samband mellan procentandelen omhäckningar och medelantalet "stora" ungar per häckande par under olika år (Spearman $r_{s}=0,30, N=10$ år, ej sign., data från Appendix 1).

Väderförhållandena under maj påverkade inte benägenheten till omhäckningar ( $S$ pearman $r_{s}=0,04$ resp. $-0,25$ för jämförelser mellan procentandelen omhäckningar och temperaturen resp. nederbörden, $\mathrm{N}=10$ år, ej sign.). Däremot fanns en tendens till större benägenhet för omhäckningar under år med låg nederbörd i juni (Spearman $r_{s}=-0,47, N=10$ år, $0,05<\mathrm{P}<0,10)$, medan junitemperaturen tycks ha varit av mindre betydelse (Spearman $r_{s}=0,22, N=10$ år, ej sign.).

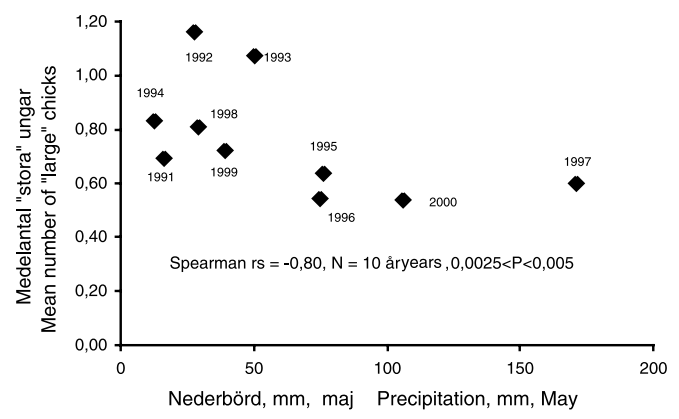

Figur 7. Ungproduktionen i relation till nederbörden under maj.

Production of young in relation to precipitation in May.

Genomsnittligt mediandatum för ruvningsstart av misslyckade kullar som följdes av en omhäckning var den 27 maj (median av mediandatum för fem år), jämfört med 2 juni för misslyckade "första"-kullar som inte följdes av någon omhäckning (jämförelsen omfattade 1991, 1992, 1994, 1996 och 1997, uppgifter om ruvningsstart för kullar följda av omhäckning saknas för de övriga åren, Wilcoxons parvisa rangtest, $\mathrm{P}=0,43$, tvåsidigt, ej sign.). Det fanns alltså ingen tydlig "kalender"-effekt i form av en minskad benägenhet till omhäckning senare under häckningssäsongen. Däremot var benägenheten till omhäckning större i de fall när ruvningen avbrutits under första eller andra veckan, jämfört med senare. Det genomsnittliga antalet exponeringsdagar, beräknade med Mayfield-metoden, var 13 dagar (medelvärde för 10 år) för misslyckade "första"-häckningar som följdes av en omhäckning, jämfört med 19 dagar för misslyckade kullar ej följda av någon omhäckning (Wilcoxons parvisa rangtest, $\mathrm{P}=0,03$, tvåsidigt). Dessa data antyder också att reproduktionskostnader i samband med den första kullen påverkar tendensen till omhäckningsförsök.

\section{Ungkullarnas överlevnad till flygg ålder}

Procentandelen ungkullar med två "stora" ungar minskade över undersökningsperioden (Figur 8). Det fanns ett tydligt samband mellan procentandelen lyckade häckningar med två "stora" ungar och medelantalet "stora" ungar per par (Figur 9), d.v.s. inte bara kläckningsframgången (Figur 5) utan också ungarnas överlevnad påverkade ungproduktionen. Det fanns också ett tydligt samband mellan mediandatum för ruvningens början av "första"- 


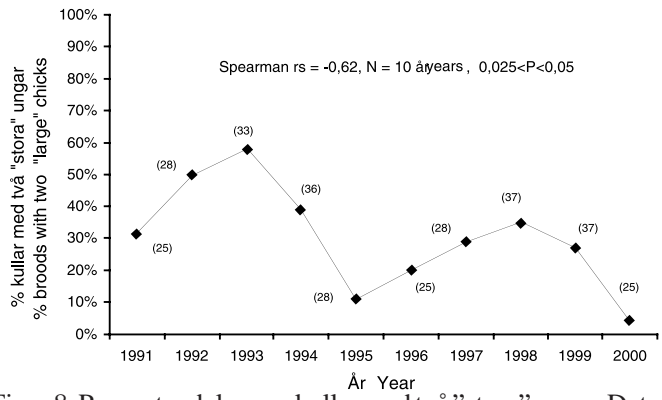

Figur 8. Procentandelen ungkullar med två"stora" ungar. Data från Appendix 1. Antalet undersökta par inom parantes.

Percentage of broods with two "large" chicks. Data from Appendix 1. Number of investigated pairs in parentheses.

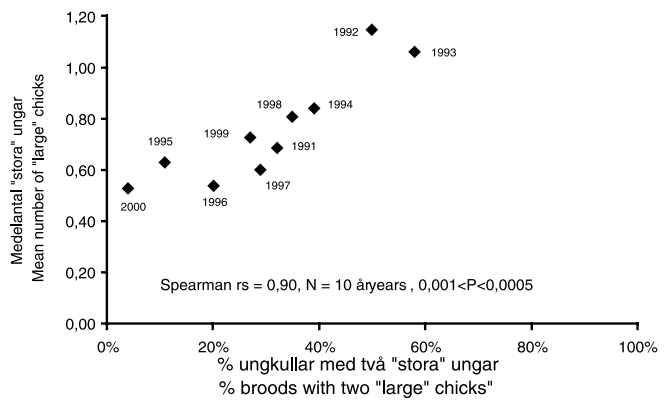

Figur 9. Sambandet mellan procentandelen ungkullar med två "stora" ungar och medelantal "stora" ungar per par (primärdata i Appendix 1).

The relationship between the percentage of broods with two "large" chicks and the mean number of "large" chicks per pair (primary data in Appendix 1).

kullar och andelen ungkullar med två "stora" ungar (Figur 10), d.v.s. en bättre överlevnad under år med tidig häckningsstart. Vi fann däremot ingen tendens till att ungarnas överlevnad var lägre för sent kläckta kullar under samma häckningssäsong (liksom man inte heller gjort på Shetlandsöarna, Gomersall 1986). Mediandatum för kläckning skiljde sig inte mellan kullar där inga ungar försvann under den period de hölls under bevakning och kullar där den ena eller båda ungarna försvann (Tabell 4, Wilcoxons parvisa rangtest, $\mathrm{P}=0,49$, tvåsidigt, ej sign.).

Andelen ungkullar där båda ungarna överlevde till "stor" ålder tenderade att vara lägre under somrar med mycket nederbörd i juni (Spearman $r_{s}=-0,54$, $\mathrm{N}=10$ år, $0,05<\mathrm{P}<0,10$ för test mot nederbörden $\mathrm{i}$ juni, data från Appendix 1), medan nederbörden i juli spelade mindre roll (Spearman $r_{s}=-0,27, N=10$ år, ej sign. data från Appendix 1). Däremot tycks

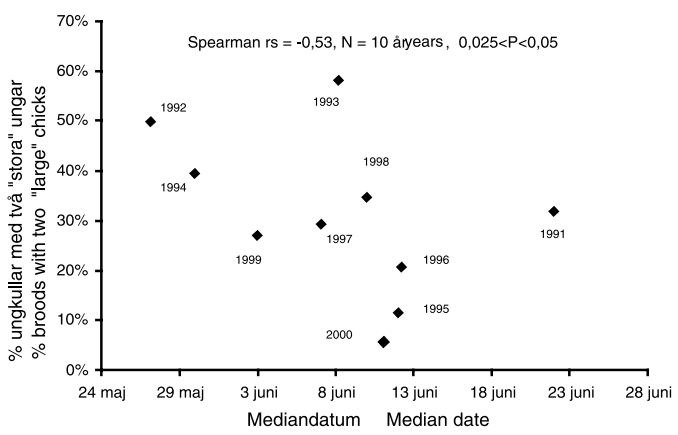

Figur 10. Procentandelen ungkullar med två "stora" ungar i relation till mediandatum för ruvningsstart av första-kullar. Data från Appendix 1 och Tabell 2.

Percentage of successful breedings with two "large" chicks in relation to median date for start of incubation of first clutches. Data from Appendix 1 and Table 1.

temperaturen ha varit av liten betydelse (Spearman $r_{s}=-0,26$ resp. 0,00 för juni resp. juli, $N=10$ år, ej sign. data från Appendix 1). Det är alltså under juni, eller de första veckorna efter kläckningen som ungarna är mest känsliga för regnigt väder.

Den individuella sannolikheten för överlevnad till flygg ålder var lägre för ungar i kullar med två ungar, jämfört med "ensam"-ungar i kullar med en unge; i

Tabell 4. Kläckningsdatum för ungkullar. Jämförelse mellan kullar utan respektive med försvunna ungar. $\mathrm{N}$ $=$ antal kullar.

Hatching dates. Comparison between broods without and with losses of chicks. $N=$ number of broods.

\begin{tabular}{|c|c|c|c|c|}
\hline \multirow[t]{2}{*}{$\begin{array}{l}\text { År } \\
\text { Year }\end{array}$} & \multicolumn{2}{|c|}{$\begin{array}{l}\text { Inga försvunna } \\
\text { No chicks lost }\end{array}$} & \multicolumn{2}{|c|}{$\begin{array}{l}1-2 \text { försvunna } \\
1-2 \text { chicks lost }\end{array}$} \\
\hline & $\mathrm{N}$ & Median & $\mathrm{N}$ & Median \\
\hline 1991 & 14 & 27 juni & 2 & 6 juli \\
\hline 1992 & 19 & 28 juni & 6 & 30 juni \\
\hline 1993 & 26 & 26 juni & 5 & 1 juli \\
\hline 1994 & 27 & 21 juni & 10 & 18 juni \\
\hline 1995 & 21 & 30 juni & 12 & 1 juli \\
\hline 1996 & 20 & 2 juli & 6 & 29 juni \\
\hline 1997 & 16 & 25 juni & 12 & 24 juni \\
\hline 1998 & 33 & 27 juni & 8 & 24 juni \\
\hline 1999 & 29 & 24 juni & 9 & 25 juni \\
\hline 2000 & 11 & 5 juli & 5 & 9 juli \\
\hline $\begin{array}{l}\text { Medel } \\
\text { Mean }\end{array}$ & & 28 juni & & 29 juni \\
\hline
\end{tabular}




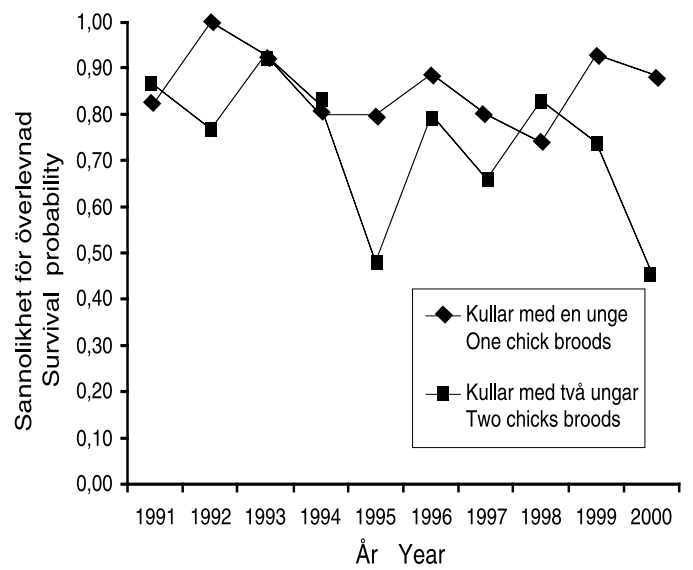

Figur 11. Individuell sannolikhet för ungarnas överlevnad till flygg ålder i kullar med en respektive två ungar (beräknat med Mayfield-metod, data från Appendix 1 och 3).

Individual chick survival until fledging age in one and two chick broods (calculated with the Mayfield method, data from Appendices 1 and 3).

genomsnitt $86 \%$ resp. $70 \%$ (Figur 11, Wilcoxons parvisa rangtest, $\mathrm{P}=0,04$, tvåsidigt). Vidare var variationen mellan åren större för ungar i kullar med två ungar, jämfört med "ensam"-ungar (Figur 11). Åtminstone vissa år kan en enskild unge öka sin egen sannolikhet för överlevnad till flygg ålder högst betydligt om den andra ungen försvinner. Vi saknar i de allra flesta fall indikationer på orsaken till att ungar försvunnit innan de blivit flygga, men från andra smålomsstudier har vi dragit slutsatsen att skillnader mellan åren i ungarnas överlevnad troligtvis är kopplad till födotillgång och matningsfrekvens. I undersökningar både i sydvästra Sverige och i Kanada har man funnit att ungarna inte matas med mer fisk än vad som precis täcker eller ligger något under det teoretiskt beräknade energibehovet (Reimchen \& Douglas 1984, Eriksson m.fl. 1990). Hungriga smålomsungar kan vara ganska aggressiva mot varandra, och det förekommer att den svagare ungen dör några dagar efter kläckningen (t.ex. von Braun m.fl. 1998, Dickson 1992, 1993, Eberl \& Pickman 1993). Vidare har man på Shetlandsöarna funnit att skillnaden i vikt mellan två halvvuxna ungar i samma kull kan uppgå till 10\%, och att en halvvuxen "ensam"-unge kan väga ungefär lika mycket som den största ungen i en kull med två ungar (Okill \& Wanless 1990). Det är också välkänt från andra fågelgrupper med s.k. asynkron häckning (d.v.s. att ungarna inte kläcker samtidigt, t.ex. rovfåglar, hägrar), att de först kläckta och större ungarna är mer framgångsrika i syskonkonkurrens om maten medan de svagare ungarna dör (t.ex. Forbes 1993 för en teoretisk översikt).

Överlevnaden för ungar i kullar med två ungar var lägre under varma somrar, vilket återspeglas i en signifikant korrelation mellan individuell överlevnad i kullar med två ungar och temperaturen i juni (Spearman $r_{s}=-0,73, N=10$ år, $0,005<\mathrm{P}<0,01$, data från Appendix 1 och 3) medan inget motsvarande samband upptäcktes för "ensam"-ungar i kullar med en unge (Spearman $r_{s}=0,21, N=10$ år, ej sign., data från Appendix 1 och 3). Det fanns ingen sådan tendens för juli (Spearman $r_{s}=-0,18$ resp. $-0,34$ för sambanden mellan individuell överlevnad i kullar med en resp. två ungar och medeltemperaturen i juli, $\mathrm{N}=10$ år, ej sign., data från Appendix 1 och 3). Den individuella skillnaden kan också ha påverkats negativt av hög nederbörd under juni, men skillnaden mellan kullar med två ungar och en unge var inte påtaglig ( Spearman $r_{s}=-0,38$ resp. $-0,46$ för sambanden mellan individuell överlevnad i kullar med två ungar respektive en unge och nederbörden $\mathrm{i}$ juni, $\mathrm{N}=10$ år, ej sign. resp. $0,05<\mathrm{P}<0,10$, data från Appendix 1 och 3). Nederbörden under juli tycks däremot sakna betydelse (Spearman $r_{s}=0,04$ resp. 0,21 för sambanden mellan individuell överlevnad i kullar med två resp. en ungar och nederbörden i juni, $\mathrm{N}=10$ år, ej sign., data från Appendix 1 och 3 ).

$\mathrm{Vi}$ vill inte utesluta att den nedåtgående trenden för procentandelen ungkullar med två "stora" ungar kan bero på en generell försämring i tillgänglighet på bytesfisk i fiskevattnen. Det finns också indikationer på att väderförhållandena, speciellt $\mathrm{i}$ juni då ungarna fortfarande är nykläckta eller ganska små, påverkar både andelen ungkullar med två "stora" ungar och den individuella överlevnaden av ungarna. Resultaten är inte helt entydiga, men kanske matningen och därmed överlevnaden för ungar i kullar med två ungar varit lägre under varma somrar. Bytesfiskens uppträdande på olika djup i fiskevattnen kan variera med vattentemperaturen och därmed påverka tillgängligheten för de fiskande smålomsföräldrarna.

\section{Förflyttningar mellan tjärnar}

I sju fall har vi kunnat fastställa att smålomsungarna har flyttat sig över land mellan olika tjärnar, som längst 350 meter (Tabell 5). Förflyttningarna har i fem fall skett från mindre till större tjärnar, alltså tvärtemot vad man kunnat förvänta sig med anledningen av ett samband mellan en större andel ungkullar med två "stora" ungar och häckning i mindre tjärnar (Tabell 10). Alternativt kan man fråga sig om 
Tabell 5. Fastställda förflyttningar över land av icke flygga smålomsungar Confirmed overland movements by non-fledged Red-throated Diver chicks.

\begin{tabular}{|c|c|c|c|c|}
\hline $\begin{array}{l}\text { Ar } \\
\text { Year }\end{array}$ & $\begin{array}{l}\text { Från } \rightarrow \text { till }^{\text {a }} \\
\text { From } \rightarrow \text { to }^{a}\end{array}$ & $\begin{array}{l}\text { Avstånd, m } \\
\text { Distance, } m\end{array}$ & $\begin{array}{l}\text { Areal, ha, } \\
\text { från } \rightarrow \text { till } \\
\text { Surface area, ha } \\
\text { from } \rightarrow \text { to }\end{array}$ & $\begin{array}{l}\text { Ungar försvunna mellan två } \\
\text { observationer då förflyttning skett } \\
\text { Loss of chicks between two observations } \\
\text { with overland movements inbetween }\end{array}$ \\
\hline 1991 & $40 \rightarrow 39$ & $350 \mathrm{~m}$ & 0,7 ha $\rightarrow 2,6$ ha & $\begin{array}{l}\text { Nej, } 2 \text { ungar } \rightarrow 2 \text { ungar } \\
\text { No, } 2 \text { chicks } \rightarrow 2 \text { chicks }\end{array}$ \\
\hline 1994 & $46 \rightarrow 36$ & $300 \mathrm{~m}$ & 0,2 ha $\rightarrow 0,5$ ha & $\begin{array}{l}\text { Nej, } 2 \text { ungar } \rightarrow 2 \text { ungar } \\
\text { No, } 2 \text { chicks } \rightarrow 2 \text { chicks }\end{array}$ \\
\hline 1996 & $38 \rightarrow 39$ & $350 \mathrm{~m}$ & 1,7 ha $\rightarrow 2,6$ ha & $\begin{array}{l}\text { Nej, } 1 \text { unge } \rightarrow 1 \text { unge } \\
\text { No, } 1 \text { chick } \rightarrow 1 \text { chick }\end{array}$ \\
\hline 1999 & $46 \rightarrow 36$ & $300 \mathrm{~m}$ & 0,2 ha $\rightarrow 0,5$ ha & $\begin{array}{l}\text { Ja, } 2 \text { ungar } \rightarrow 1 \text { unge } \\
\text { Yes, } 2 \text { chicks } \rightarrow 1 \text { chick }\end{array}$ \\
\hline 2000 & $\begin{array}{l}9 \rightarrow \text { inget nummer } \\
\text { no number }\end{array}$ & $200 \mathrm{~m}$ & 0,4 ha $\rightarrow 0,4$ ha & $\begin{array}{l}\text { Nej, } 1 \text { unge } \rightarrow 1 \text { unge } \\
\text { No, } 1 \text { chick } \rightarrow 1 \text { chick }\end{array}$ \\
\hline 2000 & $29 \rightarrow 28$ & $200 \mathrm{~m}$ & $0,8 \mathrm{ha} \rightarrow 0,7 \mathrm{ha}$ & $\begin{array}{l}\text { Ja, } 2 \text { ungar } \rightarrow 1 \text { unge } \\
\text { Yes, } 2 \text { chicks } \rightarrow 1 \text { chick }\end{array}$ \\
\hline 2000 & $79 \rightarrow 81$ & $200 \mathrm{~m}$ & 0,1 ha $\rightarrow 0,3$ ha & $\begin{array}{l}\text { Nej, } 1 \text { unge } \rightarrow 1 \text { unge } \\
\text { No, } 1 \text { chick } \rightarrow 1 \text { chick }\end{array}$ \\
\hline
\end{tabular}

${ }^{a}$ Tjärnarna numrerade enligt Appendix 4.

a Tarns numbered according to Appendix 4.

förflyttningar till en större tjärn kan förklaras med att det blir lättare för föräldrafåglarna att starta och landa i samband med födosöksturerna. I två fall hade en unge försvunnit i samband med att en förflyttning över land konstaterats mellan två observationstillfällen. Vi har vid två andra tillfällen konstaterat att smålomsungar har landat i närliggande tjärnar i samband med de första flygförsöken (kanske tjärnarna de landat i varit bättre lämpade för fortsatt flygträning?). I båda fallen var ungarna fortfarande så dåliga flygare att de kunde fångas för ringmärkning.

Bland andfåglar förekommer det regelmässigt att icke flygga ungar flyttar över land mellan olika sjöar. Sådana förflyttningar tycks vara förknippade med en ökad risk för att ungar försvinner (t.ex. Ball m.fl. 1975 för gräsand Anas platyrhynchos, Alison 1976 för alfågel Clangula hyemalis, Duncan 1983 för stjärtand Anas acuta). I vissa fall tycks emellertid riskerna balanseras mot en bättre födotillgång i de vatten dit ungarna flyttar (t.ex. Eriksson 1978 för knipa Bucephala clangula).
Häckningsframgång med hänsyn till boets storlek och placering

Bon med kläckta kullar var något större, ungefär 1 $\mathrm{cm}$ för såväl största som minsta diameter (Tabell 6). Detta kan vara en indikation på att större individer är mer framgångsrika, förutsatt att storvuxna individer i regel bygger större bon och att bostorleken svarar mot storleken av den största fågeln i paret. Men bostorleken kan även ha påverkats av andra faktorer. Boet blir, beroende på underlaget, rimligtvis mera nedlegat ju längre ruvningen framskridit. Storleken kan också påverkas av om det använts som viloplats efter kläckningen.

Avståndet mellan bo och vattenbryn varierade från $7 \mathrm{~cm}$ till $67 \mathrm{~cm}$ och med nästan samma medelavstånd (22 resp. $21 \mathrm{~cm}$.) för bon med respektive utan kläckning (Tabell 6). För häckningar på småöar fanns en indikation på att medelavståndet till fast land var något större för kläckta kullar, jämfört med icke kläckta, 8,6 m. resp. 6,1 m., men skillnaden var inte statistiskt signifikant (Tabell 6). 
Tabell 6. Jämförelse av bostorlek, avstånd från bo till vatten och avstånd mellan häckningsö och land för bon med kläckta respektive okläckta kullar. Antalet undersökta bon inom parentes. P = Signifikans för skillnaderna med Wilcoxons parvisa rangtest, tvåsidigt.

Comparison of nest size, distances from nest to water edge, and distance from nesting islet to mainland for hatched and failed clutches. Number of nests in parentheses. $P=$ Significance for the differences with Wilcoxon signed rank test, two-tailed.

\begin{tabular}{|c|c|c|c|c|c|c|c|c|}
\hline \multirow[b]{3}{*}{$\begin{array}{l}\text { År } \\
\text { Year }\end{array}$} & \multicolumn{4}{|c|}{$\begin{array}{l}\text { Bostorlek, medelvärde per bo } \\
\text { Nest size, mean per nest }\end{array}$} & \multirow{2}{*}{\multicolumn{2}{|c|}{$\begin{array}{l}\text { Bo till vatten, } \mathrm{cm} \\
\text { Nest to water, } \mathrm{cm}\end{array}$}} & \multicolumn{2}{|c|}{$\begin{array}{l}\text { Häckningsö till land, } \mathrm{m} \\
\text { Nest islet to land, } m\end{array}$} \\
\hline & \multicolumn{2}{|c|}{ Max. diameter, cm } & \multicolumn{2}{|c|}{ Min. diameter, $\mathrm{cm}$} & & & & \\
\hline & $\begin{array}{l}\text { Kläckt } \\
\text { Hatched }\end{array}$ & $\begin{array}{l}\text { Ej kläckt } \\
\text { Unhatched }\end{array}$ & $\begin{array}{l}\text { Kläckt } \\
\text { Hatched }\end{array}$ & $\begin{array}{l}\text { Ej kläckt } \\
\text { Unhatched }\end{array}$ & $\begin{array}{l}\text { Kläckt } \\
\text { Hatched }\end{array}$ & $\begin{array}{l}\text { Ej kläckt } \\
\text { Unhatched }\end{array}$ & $\begin{array}{l}\text { Kläckt } \\
\text { Hatched }\end{array}$ & $\begin{array}{l}\text { Ej kläckt } \\
\text { Unhatched }\end{array}$ \\
\hline 1991 & $23,7(17)$ & $22,2(9)$ & 22,8 (17) & 21,7 (9) & 20,9 (17) & $24,2(9)$ & 7,3 (14) & $6,2(7)$ \\
\hline 1992 & $23,3(36)$ & 22,2 (11) & $22,3(36)$ & $21,8(11)$ & $23,0(34)$ & $18,6(11)$ & $11,2(31)$ & $3,1(8)$ \\
\hline 1993 & 23,0 (35) & 22,2 (14) & 21,9 (35) & $21,6(14)$ & $19,4(34)$ & 20,9 (14) & $10,0(31)$ & 7,4 (11) \\
\hline 1994 & $23,8(38)$ & $23,0(21)$ & $22,7(38)$ & $22,2(21)$ & $22,5(40)$ & $23,7(22)$ & $9,8(35)$ & $4,8(17)$ \\
\hline 1995 & $23,8(34)$ & $23,3(17)$ & $23,2(34)$ & $22,5(17)$ & $22,7(34)$ & $20,1(18)$ & $7,1(28)$ & $6,0(16)$ \\
\hline 1996 & 27,0 (27) & $25,8(31)$ & 25,9 (27) & $25,0(31)$ & 20,3 (27) & $17,8(31)$ & $9,1(19)$ & $6,7(28)$ \\
\hline 1997 & $25,0(33)$ & $24,0(28)$ & 23,9 (33) & $23,2(28)$ & $23,7(33)$ & $22,7(26)$ & $5,9(31)$ & $8,6(20)$ \\
\hline $\begin{array}{l}\text { Medel } \\
\text { Mean }\end{array}$ & 24,2 & 23,2 & 23,2 & 22,6 & 21,8 & 21,1 & 8,6 & 6,1 \\
\hline $\mathrm{P}$ & \multicolumn{2}{|c|}{0,016} & \multicolumn{2}{|c|}{0,016} & \multicolumn{2}{|c|}{ Ej sign. N.S. } & \multicolumn{2}{|c|}{0,12} \\
\hline
\end{tabular}

Anmärkning: Antalet undersökta bon är för vissa år större än vad som redovisas i underlaget för beräkningar av ungproduktionen (Appendix 1, Figur 3), eftersom materialet även innefattar mätningar av bon där häckningsresultatet inte följts upp eller där häckningen upptäckts först i samband med observation av kläckta ungar.

Note: The number of investigated nests is, for some years, larger than the sample sizes given for the calculations of production of young (Appendix 1, Figure 3), because the material also includes nests where the breeding result was not followed up or the breeding was not detected until after hatching.

Boplatstrohet samt byte av boplats och häckningstjärn mellan häckningssäsongerna

Det fanns en tydlig tendens till att huvuddelen av häckningarna sker i ett begränsat antal tjärnar som nyttjats under flera år. 40 tjärnar $(42 \%$ av de 95 undersökta tjärnarna) nyttjades under minst $75 \%$ av de år de besökts. De övriga nyttjades mera sporadiskt, och 16 av dem (17\%) mindre än $25 \%$ av de år de undersökts (Figur 12). Fördelningen av tjärnarna med avseende på hur ofta de nyttjats av häckande smålommar skiljde sig signifikant från vad som kan förväntas om de häckande paren valde tjärnar rent slumpmässigt $\left(\mathrm{Chi}^{2}=15,69, \mathrm{df}=3, \mathrm{P}<0,01\right.$, tvåsidigt). Resultatet visar således på en ganska stor grad av boplatstrohet, vilket är i överensstämmelse med resultat av ringmärkningsstudier av häckande smålommar på Shetlandsöarna (Okill 1992).

Men det förekommer att boplatser överges, och det finns en generell tendens hos skilda fågelarter till en ökad benägenhet att byta till en ny boplats efter misslyckad häckning (t.ex. Dow \& Fredga 1983 för holkhäckande knipor, Harvey m.fl. 1979 för talgoxar Parus major). Mot denna bakgrund har vi undersökt om tendensen till att byta till en ny boplats vid samma tjärn, eller att en häckningstjärn överges, är

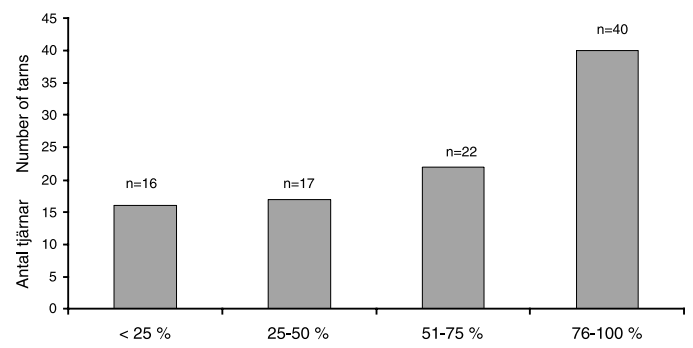

Figur 12. De 95 häckningstjärnarna grupperade med avseende på procentandelen år med häckning (primärdata från Appendix 4).

The 95 breeding tarns grouped with reference to the percentage of years with breeding (primary data from Appendix 4) 
kopplad till häckningsframgången. I genomsnitt följdes $64 \%$ av alla häckningar som ledde fram till kläckning av en ny häckning på samma boplats följande år, medan motsvarande genomsnitt var $47 \%$ för icke kläckta kullar. Tendensen till att byta till ny boplats vid samma tjärn efter ett misslyckande varierade emellertid starkt mellan de olika åren, och bara för ett år kunde den fastställas med statistisk signifikans (Tabell 7). Sett över hela undersökningsperioden, noterades en större procentandel byten till en annan boplats följande år bland icke kläckta kullar, jämfört med kläckta kullar, vid sju av nio parvisa jämförelser mellan två år (Tabell 7; teckentest: $\mathrm{N}=9$ år, $\mathrm{P}=0,18$, tvåsidigt).

Det fanns en mer tydlig tendens till ökad benägenhet att överge en häckningstjärn efter att häckningen misslyckades. I genomsnitt följdes $85 \%$ av alla lyckade häckningar av en ny häckning vid samma tjärn följande år, medan en misslyckad häckning följdes av häckning vid samma tjärn året därpå i 66\% av fallen. Tendensen noterades vid samtliga parvisa jämförelser mellan två påföljande år (Tabell 8 ; teckentest: $\mathrm{N}=9$ år, $\mathrm{P}=0,04$, tvåsidigt). Men även ten-

Tabell 7. Frekvensen av boplatsbyten inom en och samma tjärn mellan två följande år. $\mathrm{P}=$ signifikans enligt Fisher-test, tvåsidig.

The frequency of changes of nest location at the same breeding tarn between two consecutive years. $P=$ significance with Fisher exact test, two-tailed.

\begin{tabular}{|c|c|c|c|c|}
\hline \multirow[b]{2}{*}{$\begin{array}{l}\text { Ar } \\
\text { Year }\end{array}$} & & \multicolumn{2}{|c|}{$\begin{array}{l}\text { Antal (\%) kullar } \\
\text { Number (\%) of clutches }\end{array}$} & \multirow[b]{2}{*}{$\mathrm{P}$} \\
\hline & & $\begin{array}{l}\text { Samma } \\
\text { Same }\end{array}$ & $\begin{array}{l}\text { Byte } \\
\text { Change }\end{array}$ & \\
\hline \multirow[t]{2}{*}{1991} & Kläckta Hatched & $7(55 \%)$ & $6(46 \%)$ & Ej sign. \\
\hline & Okläckta Unhatched & $8(88 \%)$ & $1(11 \%)$ & N.S. \\
\hline \multirow[t]{2}{*}{1992} & Kläckta Hatched & $21(75 \%)$ & $7(25 \%)$ & 0,008 \\
\hline & Okläckta Unhatched & $0(0 \%)$ & $4(100 \%)$ & \\
\hline \multirow[t]{2}{*}{1993} & Kläckta Hatched & $14(45 \%)$ & $17(55 \%)$ & Ej sign. \\
\hline & Okläckta Unhatched & $5(42 \%)$ & $7(58 \%)$ & N.S. \\
\hline \multirow[t]{2}{*}{1994} & Kläckta Hatched & $21(70 \%)$ & $9(30 \%)$ & 0,11 \\
\hline & Okläckta Unhatched & $4(36 \%)$ & $7(64 \%)$ & \\
\hline \multirow[t]{2}{*}{1995} & Kläckta Hatched & $17(59 \%)$ & $12(41 \%)$ & Ej sign. \\
\hline & Okläckta Unhatched & $4(40 \%)$ & $6(60 \%)$ & N.S. \\
\hline \multirow[t]{2}{*}{1996} & Kläckta Hatched & $11(48 \%)$ & $12(52 \%)$ & Ejsign. \\
\hline & Okläckta Unhatched & $11(50 \%)$ & $11(50 \%)$ & N.S. \\
\hline \multirow[t]{2}{*}{1997} & Kläckta Hatched & $16(70 \%)$ & $7(30 \%)$ & Ejsign. \\
\hline & Okläckta Unhatched & $12(60 \%)$ & $8(40 \%)$ & N.S. \\
\hline \multirow[t]{2}{*}{1998} & Kläckta Hatched & $31(86 \%)$ & $5(14 \%)$ & Ej sign. \\
\hline & Okläckta Unhatched & $7(58 \%)$ & $5(42 \%)$ & N.S. \\
\hline \multirow[t]{2}{*}{1999} & Kläckta Hatched & $35(65 \%)$ & $8(35 \%)$ & Ej sign. \\
\hline & Okläckta Unhatched & $5(45 \%)$ & $6(55 \%)$ & $N . S$. \\
\hline
\end{tabular}

densen till att överge häckningstjärnen efter en misslyckade häckning varierade påtagligt mellan olika år, och den var statistiskt signifikant bara för enstaka år (Tabell 8). I flera fall var häckningstjärnen övergiven bara under något-några enstaka år, varefter den åter nyttjades av ett häckande smålomspar. Också på Shetlandsöarna och i tundraområden i Kanada har man funnit att smålommarna är benägna att överge en häckningstjärn efter ett misslyckande (Gomersall 1986, Dickson 1993).

\section{Orsaker till misslyckade häckningar}

Det är ofta svårt att fastställa orsaken till att en häckning misslyckats. För över hälften av alla misslyckade häckningar fann vi inga indikationer på tänkbara orsaker (Tabell 9). Vidare är vissa orsaker, t.ex. att boet har översvämmats efter en vattenståndshöjning, lättare att fastställa än om boet har varit utsatts för till exempel predation eller övergivits efter en störning.

Predation var den vanligaste förmodade orsaken till att en häckning misslyckats (Tabell 9). I regel

Tabell 8. Frekvens byten av häckningstjärn mellan år för lyckade och misslyckade häckningar. $\mathrm{P}=$ signifikans med Fisher-test, tvåsidig.

The frequency of changes of nesting tarns between years for successful and failed breeding attempts. $P=$ significance with Fisher exact test, two-tailed.

\begin{tabular}{|c|c|c|c|c|}
\hline \multirow[b]{2}{*}{$\begin{array}{l}\text { År } \\
\text { Year }\end{array}$} & & \multicolumn{2}{|c|}{$\begin{array}{l}\text { Antal (\%) häckningar } \\
\text { Number (\%) of breedings }\end{array}$} & \multirow[b]{2}{*}{$\mathrm{P}$} \\
\hline & & $\begin{array}{l}\text { Samma } \\
\text { Same }\end{array}$ & $\begin{array}{l}\text { Byte } \\
\text { Change }\end{array}$ & \\
\hline \multirow[t]{2}{*}{1991} & Lyckade Successful & $17(71 \%)$ & $7(29 \%)$ & Ej sign. \\
\hline & Misslyckade Failed & $8(62 \%)$ & $5(38 \%)$ & N.S. \\
\hline \multirow[t]{2}{*}{1992} & Lyckade Successful & $27(90 \%)$ & $3(10 \%)$ & 0,084 \\
\hline & Misslyckade Failed & $3(50 \%)$ & $3(50 \%)$ & \\
\hline \multirow[t]{2}{*}{1993} & Lyckade Successful & $29(91 \%)$ & $3(9 \%)$ & Ej sign. \\
\hline & Misslyckade Failed & $13(76 \%)$ & $4(24 \%)$ & N.S. \\
\hline \multirow[t]{2}{*}{1994} & Lyckade Successful & $27(77 \%)$ & $8(23 \%)$ & Ej sign. \\
\hline & Misslyckade Failed & $13(56 \%)$ & $10(43 \%)$ & N.S. \\
\hline \multirow[t]{2}{*}{1995} & Lyckade Successful & $24(96 \%)$ & $1(4 \%)$ & 0,075 \\
\hline & Misslyckade Failed & $17(74 \%)$ & $6(26 \%)$ & \\
\hline \multirow[t]{2}{*}{1996} & Lyckade Successful & $23(85 \%)$ & $4(1 \%)$ & Ej sign. \\
\hline & Misslyckade Failed & $22(79 \%)$ & $6(21 \%)$ & N.S. \\
\hline \multirow[t]{2}{*}{1997} & Lyckade Successful & $26(93 \%)$ & $2(7 \%)$ & Ej sign. \\
\hline & Misslyckade Failed & $23(82 \%)$ & $5(18 \%)$ & N.S. \\
\hline \multirow[t]{2}{*}{1998} & Lyckade Successful & $33(92 \%)$ & $3(8 \%)$ & 0,044 \\
\hline & Misslyckade Failed & $17(68 \%)$ & $8(32 \%)$ & \\
\hline \multirow[t]{2}{*}{1999} & Lyckade Successful & $22(67 \%)$ & $11(33 \%)$ & Ej sign. \\
\hline & Misslyckade Failed & $14(50 \%)$ & $14(50 \%)$ & N.S. \\
\hline
\end{tabular}


Tabell 9. Orsaker till misslyckade häckningar, sammanlagda uppgifter 1991-2000. $\mathrm{N}=$ antal häckningar, $\mathrm{L}=\%$ lyckade häckningar, $\mathrm{P}$ = predation, $\mathrm{O}$ = översvämmat bo p.g.a. höjt vattenstånd, $\mathrm{K}=$ störning av kanadagäss, $\mathrm{H}=$ störning av människor, $\mathrm{F}$ = kringflytande boö, $\mathrm{D}$ = fynd av död adult fågel, ? = okänd anledning eller ingen information, $\mathrm{M}=$ andelen kläckta kullar där inga ungar nått "stor" ålder.

Reasons for breeding failures, pooled data for 1991-2000. $N=$ number of breeding attempts, $L=$ successful breeding attempts, $P=$ predation, $\ddot{O}=$ flooded nest due to raising water level, $K=$ disturbance by Canada Geese, $H=$ human distrubance, $F=$ floating nest islet, $D=$ dead adult found, ? = unknown reason or no information, $M$ = hatched clutches but no "large" chicks.

\begin{tabular}{|c|c|c|c|c|c|c|c|c|c|c|}
\hline \multirow[t]{2}{*}{$\begin{array}{l}\text { Ar } \\
\text { Year }\end{array}$} & \multirow[b]{2}{*}{$\mathrm{N}$} & \multirow[b]{2}{*}{ L\% } & \multicolumn{5}{|c|}{$\begin{array}{l}\text { \% häckningar misslyckade före kläckning } \\
\text { \% breeding attempts failed before hatching }\end{array}$} & \multirow[b]{2}{*}{$\mathrm{D} \%$} & \multirow[b]{2}{*}{$? \%$} & \multirow[b]{2}{*}{ M\% } \\
\hline & & & $\mathrm{P} \%$ & Ö\% & $\mathrm{K} \%$ & $\mathrm{H} \%$ & $\mathrm{~F} \%$ & & & \\
\hline 1991 & 29 & 52 & 7 & 3 & - & - & - & - & 31 & 7 \\
\hline 1992 & 33 & 76 & 18 & - & - & - & - & - & 3 & 3 \\
\hline 1993 & 47 & 66 & 17 & - & 4 & - & - & - & 11 & 4 \\
\hline 1994 & 58 & 60 & 5 & - & 2 & 3 & - & - & 22 & 7 \\
\hline 1995 & 49 & 57 & 2 & - & 2 & - & 2 & - & 25 & 12 \\
\hline 1996 & 56 & 45 & 7 & 2 & 9 & - & - & - & 35 & 2 \\
\hline 1997 & 53 & 47 & 8 & - & - & 2 & - & 2 & 32 & 9 \\
\hline 1998 & 58 & 60 & - & - & - & - & - & - & 29 & 10 \\
\hline 1999 & 64 & 58 & 3 & 2 & - & 2 & 2 & - & 33 & 2 \\
\hline 2000 & 40 & 50 & 8 & - & - & - & - & - & 43 & - \\
\hline $\begin{array}{l}\text { Medel } \\
\text { Mean }\end{array}$ & & 57 & 8 & 0,7 & 2 & 0,7 & 0,4 & 0,2 & 26 & 6 \\
\hline
\end{tabular}

baserades bedömningen på fynd av äggskal eller observationer av spårstämplar från tänkbara predatorer i boets omedelbara närhet. Under fältarbetet har indikation på äggpredation från rödräv Vulpes vulpes, korp Corvus corax, trana Grus grus samt måsfåglar noterats. I tidigare undersökningar av smålom i såväl Nordamerika (t.ex. Eberl \& Picman 1993, Dickson 1993) som i Sverige (Västerbottens kustland, Skyllberg m.fl. 1999) har man bedömt att predation av ägg eller ungar är en viktig orsak till misslyckanden. Vi misstänker att predation är orsaken till flera av de misslyckanden som redovisats som "okänd anledning" i vårt material. Dessutom kan störningar och predation vara svåra att separera som tänkbara orsaker. För storlom har man således visat att predationsrisken för ett bo ökar om den ruvande fågeln har lämnat boet efter en störning (Götmark m.fl. 1988, 1990).

Höjt vattenstånd och översvämmade bon. I bara tre fall har vi bedömt att en vattenståndshöjning har bidragit till att en häckning avbrutits. I viss utsträckning kan de gungflyartade stränder, där smålommen ofta placerar sitt bo, flyta upp eller ned i takt med variationer $i$ vattenståndet, varför smålommen antagligen är mindre sårbar än t.ex. storlommen för att bon dränks i samband med stigande vattenstånd. Vi tror alltså inte att vattenståndsvariationer har varit någon dominerande orsak till misslyckanden. Samma bedömning har man gjort på Shetlandsöarna (Gomersall 1986).

Störningar av kanadagäss. I nio fall har vi bedömt att störningar av kanadagäss Branta canadensis låg bakom misslyckandet, med ledning av fynd av söndertrampade smålomsägg och spillning från gäss i boet. Även om kanadagässens expansion inte har bedömts utgöra något hot för häckande smålommar i regionalt eller nationellt perspektiv (Eriksson \& Lindberg 2000b), kan alltså enstaka par missgynnas.

Störningar av människor. Bara i fem fall har vi bedömt att störningar av människor (fiskare m.m.) har bidragit till misslyckanden, men med reservationen att denna faktor är svår att utvärdera och separera från predation (se ovan).

Kringflytande boöar. I två fall har vi noterat att häckningen avbrutits sedan boön slitits loss och flutit runt i tjärnen, men det finns också exempel på att smålomspar fullföljt ruvningen i sådana fall.

Döda föräldrafåglar. Vi har ingen uppfattning om i vilken utsträckning misslyckade häckningar kan kopplas till att föräldrafåglar dött, men rimligtvis försvinner döda fåglar ofta snabbt och kan därför vara underrepresenterade i materialet. Vid tre tillfäl- 
len har en misslyckad häckning kunnat kopplas till ett fynd av en död vuxen fågel. I ett av fallen hade en ruvande fågel slagits av en rovfågel, troligen duvhök Accipiter gentilis eller berguv Bubo bubo, medan dödsorsaken inte har fastställts för de två andra fåglarna. I den mån sjukdom eller svält bidragit till en försämrad kondition hos fåglarna, kan detta dessutom ha gjort dem mer sårbara för predatorer. Vidare har vi vid en av fiskesjöarna gjort ett makabart fynd av en adult smålom som hittats med ett fiskedrag, lina och metspö på släp.

Dödlighet bland ungarna. Hos lommarna kläcks vanligen båda äggen, men erfarenhetsmässigt vet man att en unge ofta försvinner ganska snart efter kläckningen, troligtvis till följd av svält och ibland i kombination med aggressivitet mellan ungarna (se ovan). Rimligtvis har alltså ungar försvunnit under de allra första dagarna efter kläckningen i betydligt större omfattning än vi kunnat fastställa under fältarbetet. I de allra flesta fall, när vi kunnat fastställa att ungarna har försvunnit innan de nått "stor" ålder, finns emellertid ingen indikation på orsaken. Predation från rödräv eller gädda Esox lucius misstänks i tre fall. Döda ungar har påträffats vid sex tillfällen, vilket antyder att svält eller sjukdom åtminstone $\mathrm{i}$ enstaka fall är orsaken till misslyckanden. I flertalet fall var ungen liten-halvvuxen, men en av dem var nästan flygg.

\section{Häckningsframgången i relation till egenskaper hos häckningstjärnarna}

Det finns ett ganska svagt men statistiskt signifikant samband mellan procentandelen år med häckning och ungproduktionen (Spearman $r_{s}=0,25, N=91$ tjärnar, $\mathrm{P}=0,009$, data från Appendix 4). Detta tyder på att det kan finnas någon eller några bakomliggande faktorer som påverkar såväl attraktiviteten som ungproduktionen i de olika tjärnarna.

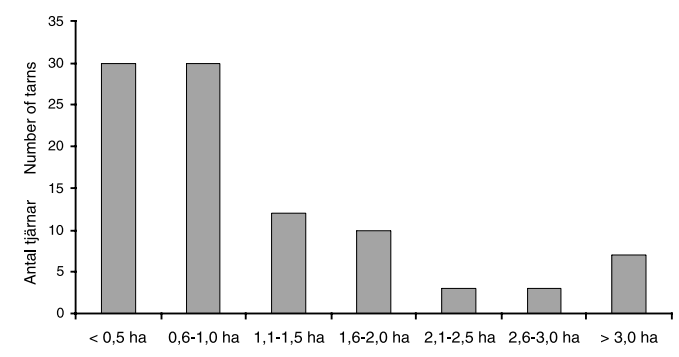

Figur 13. Arealfördelningen bland de 95 undersökta häckningstjärnarna.

Surface area distribution of the 95 breeding tarns.
Häckningstjärnarnas areal. Huvuddelen av häckningstjärnarna var mindre än en 1,0 ha (Figur 13), och den största tjärnen med häckning åtminstone ett år var 8,2 ha. Det finns inga indikationer på samband mellan areal och tjärnarnas attraktivitet för häckande smålommar (Tabell 10). Däremot fanns ett ganska svagt men statistiskt signifikant samband mellan ökande areal och lägre procentandel ungkullar med två "stora" ungar (Tabell 10), vilket antyder att de större tjärnarna kan ha fungerat sämre som "barnkammare" för de icke flygga ungarna. Relationen mellan tjärnarnas areal och ungarnas överlevnad har emellertid inte givit utslag i något samband mellan areal och medelantalet "stora" ungar per par (Tabell 10). Som tidigare påpekats, finns det inte heller någon indikation på att icke flygga ungars förflyttningar över land regelmässigt skulle ske från större mot mindre tjärnar.

Inte heller i sydvästra Sverige noterades 1980-96 någon tendens till samband mellan häckningstjärnarnas areal (0,5-7,0 ha) och ungproduktionen (Eriksson \& Johansson 1997). På Shetlandsöarna har man däremot noterat att framgångsrika smålomspar i första hand påträffas i små tjärnar, mindre än 0,3 ha (Okill \& Wanless 1990). Vidare var kläckningsframgången (men inte överlevnaden av kläckta ungar till flygg ålder) högre i tjärnar mindre än 1 ha (Gomersall 1986). I vårt material fanns ingen tendens till att de små tjärnarna (upptill 0,3 ha) var mer attraktiva; procentandelen år med häckning var i genomsnitt $57 \%$ för 15 små tjärnar, jämfört med $63 \%$ för 80 tjärnar större än 0,3 ha. Inte heller ungproduktionen skiljde sig mellan tjärnar upp till 0,3 ha ( 0,74 "stora" ungar per par och år) och större tjärnar (0,69 "stora" ungar per par och år; MannWhitneyt U test, ej sign.). På Shetlandsöarna försökte man koppla den högre kläckningsframgången vid små tjärnar till bland annat mindre störningar från fiskare och mera stabilt vattenstånd (Gomersall 1986, Okill \& Wanless 1990).

Avstånd till väg. Vi fann inga tendenser till att avståndet till väg påverkade tjärnarnas attraktivitet eller ungproduktionen (Tabell 10). Vi tror därför inte att störningar från rörligt friluftsliv m.m., i den mån detta är kopplat till tillgängligheten från vägar, har påverkat häckningsutfallet i de olika tjärnarna. Vid två av tjärnarna (nr 75 och 100, se Appendix 4) förekommer fritidsfiske regelbundet, och möjligen kan det låga utnyttjandet av en av dem (nr 75 med häckning bara två av tio undersökta år, Appendix 4) sättas i samband med störningar. Fritidsfiske har mera tillfälligt även noterats vid andra tjärnar.

Smålommens tillbakagång i sydvästra Sverige 
Tabell 10. Samband (Spearmans rangkorrelationskoefficient $r_{s}$ ) mellan undersökta egenskaper hos häckningstjärnarna, procentandelen år med häckning och ungproduktionen. Primärdata från appendix $4 . \mathrm{N}=$ antal tjärnar.

Relationships (Spearman rank correlation, $r_{s}$, corrected for ties) between breeding tarn characteristics, percentage of years with breeding and production of young. Primary data from Appendix 4. $N=$ number of tarns.

\begin{tabular}{|c|c|c|c|c|c|c|c|c|c|}
\hline & \multicolumn{3}{|c|}{$\begin{array}{l}\text { \% år med häckning } \\
\% \text { years with breeding }\end{array}$} & \multicolumn{3}{|c|}{$\begin{array}{l}\text { Medelantal "stora" ungar } \\
\text { per par och år } \\
\text { Mean number of "large" } \\
\text { chicks per pair and year }\end{array}$} & \multicolumn{3}{|c|}{$\begin{array}{l}\text { \% lyckade häckningarmed } \\
\text { två "stora" ungar } \\
\text { \% successful breeding with } \\
\text { two "large" chicks }\end{array}$} \\
\hline & $r_{s}$ & $\mathrm{~N}$ & $\mathrm{P}$ & $r_{s}$ & $\mathrm{~N}$ & $\mathrm{P}$ & $r_{s}$ & $\mathrm{~N}$ & $\mathrm{P}$ \\
\hline $\begin{array}{l}\text { Areal } \\
\text { Surface area }\end{array}$ & $-0,05$ & 95 & 0,31 & $-0,05$ & 91 & 0,32 & $-0,21$ & 84 & 0,03 \\
\hline $\begin{array}{l}\text { Avstånd till väg } \\
\text { Distance to road }\end{array}$ & 0,07 & 95 & 0,25 & 0,07 & 91 & 0,26 & $-0,16$ & 84 & 0,07 \\
\hline $\begin{array}{l}\text { Avstånd till fiskevatten } \\
\text { Distance to fishing water }\end{array}$ & $-0,11$ & 95 & 0,16 & 0,01 & 91 & 0,47 & $-0,19$ & 84 & 0,04 \\
\hline
\end{tabular}

under mitten av 1900-talet kunde inte relateras till att tjärnar i närheten av vägar eller bebyggelse skulle ha övergivits i större utsträckning än mer avlägset belägna (och förmodad mindre störda) tjärnar (Eriksson m.fl. 1988). Inte heller på Shetlandsöarna noterade man någon tendens till lägre häckningsframgång för smålomspar häckande nära vägar (Gomersall 1986). Däremot fanns i vårt material ett svagt och svårtolkat samband mellan en lägre andel ungkullar med "två" stora ungar i tjärnar på långt avstånd från väg (Tabell 10).

Avstånd till fiskevatten. Flertalet av häckningstjärnarna låg koncentrerade på ett avstånd mindre än 1 $\mathrm{km}$ från fiskevattnen (Figur 14), och som längst var två tjärnar (med häckning 13\% resp. $78 \%$ av de undersökta åren) belägna 4,6 km från fiskevattnen. Vi fann ingen tendens till att avståndet till närmaste fiskevatten påverkade tjärnarnas attraktivitet eller ungproduktionen (Tabell 10). Procentandelen ungkullar med två "stora" ungar var däremot lägre $\mathrm{i}$ tjärnar belägna på längre avstånd från fiskevattnen (Tabell 10), vilket antyder att matningsfrekvensen och därmed ungarnas överlevnad var något lägre. Men denna effekt har inte givit utslag i något samband med medelungproduktionen.

I sydvästra Sverige fann man 1980-96 att häckningsframgången var högre i tjärnar belägna nära fiskesjöarna (Eriksson \& Johansson 1997). Materialet omfattade bara 19 tjärnar men spännvidden i avstånd till närmaste fiskevatten var större, $0,7-13,1$ km. Från en kanadensisk undersökning (Eberl \& Picman 1993) kan man dra slutsatsen att kläckningsframgången tycks vara oberoende av avståndet till fiskevattnen, men att det tycks finnas ett tröskelvär- de vid ungefär $9 \mathrm{~km}$ där transporten av bytesfisk blir så krävande att matningsfrekvensen och därmed ungarnas överlevnad påverkas. I undersökningar på Shetlandsöarna (Merrie 1978) och i Kanada (Douglas \& Reimchen 1988a) fann man sällan några smålomspar häckande på större avstånd än 8-9 km från fiskevattnen.

I vårt material var således alla häckningstjärnar belägna så nära fiskesjöarna att vi knappast borde ha förväntat oss någon tydlig påverkan. Vi tror att detta också gäller för andra undersökningar där man inte funnit några samband mellan häckningsframgång och avstånd till fiskevattnen. I Västerbottens kustland fanns således inget samband mellan häckningsframgång och avståndet till fiskevatten för smålomspar häckande 0,3-4,0 km från kusten (Skyllberg m.fl. 1999). För havsfiskande smålomspar på Shetlandsöarna fann man ingen skillnad i häcknings-

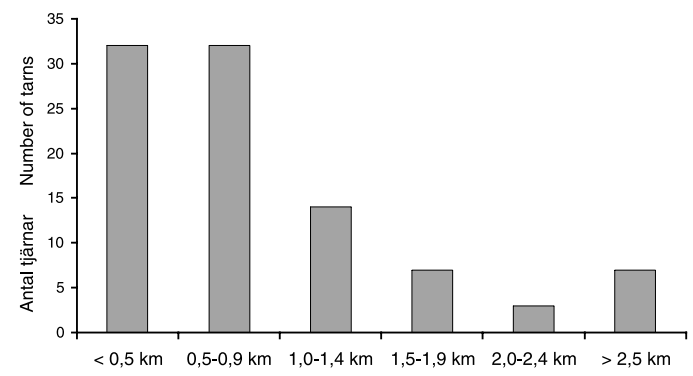

Figur 14. Avståndet till fiskevatten för samma 95 häckningstjärnar som i Figur 13.

Distance to fishing water among the same 95 breeding tarns as in Figure 13. 
framgången i en jämförelse mellan tjärnar belägna på mindre respektive större avstånd än $1 \mathrm{~km}$ från havet (Gomersall 1986). Men med referens till andra studier kan man ifrågasätta om just 1 km-gränsen är relevant för en sådan jämförelse.

Förekomst av lämpliga boöar. Det fanns ingen tendens till att tjärnar med lämpliga häckningsöar var mer attraktiva för häckande smålommar än tjärnar utan häckningsöar. Den genomsnittliga procentandelen år med häckning var 63\% resp. 56\% (MannWhitney U-test, $\mathrm{n}=83$ resp. 12 tjärnar, $\mathrm{P}=0,44$, tvåsidigt). Ungproduktionen var $\mathrm{i}$ genomsnitt något högre i tjärnar med lämpliga häckningsöar, 0,71 "stora" ungar per år jämfört med 0,61 "stora" ungar per år för tjärnar utan lämpliga häckningsöar, men skillnaden var inte statistiskt signifikant (MannWhitney U-test, $\mathrm{n}=79$ resp. 12 tjärnar, $\mathrm{P}=0,28$, tvåsidigt). Andelen ungkullar med två "stora" ungar skiljde sig inte mellan tjärnar med respektive utan lämpliga boöar, 30\% resp. 33\% (Mann-Whitney Utest, $\mathrm{n}=73$ resp. 11 tjärnar, $\mathrm{P}=0,84$, tvåsidigt).

I södra Finland och i Kanada har man noterat att häckningsframgången var högre för smålomspar häckande på öar (Lokki \& Eklöf 1984, Douglas \& Reimchen 1988b). För ett havsfiskande smålomsbestånd i Västerbottens kustland noterades lyckade häckningar enbart för smålomspar häckande på småöar (Skyllberg m.fl. 1999). På Shetlandsöarna fann man 1981-83 däremot ingen tendens till att smålomspar häckande på småöar skulle vara mer framgångsrika, men predationsbilden där var annorlunda med enbart fåglar (t.ex. havstrut Larus marinus, labb Stercorarius parasiticus och storlabb Stercorarius skua) som predatorer (Gomersall 1986). Att placera boet på en ö kan alltså vara av betydelse för kläckningsframgången om risken för predation från däggdjur är påtaglig, men däremot kanske av mindre betydelse när fåglar är de dominerande predatorerna.

Genomströmmande vatten. Möjligen var tjärnar med genomströmmande vatten något mer attraktiva för häckande smålommar: Den genomsnittliga procentandelen år med häckning var 69\% resp. 59\% (Mann-Whitney U-test, $\mathrm{n}=23$ resp. 72 tjärnar, $\mathrm{P}=0,13$, tvåsidigt). Även ungproduktionen var högre vid tjärnar med genomströmmande vatten; 0,81 resp. 0,66 "stora" ungar per år (Mann-Whitney U-test, $\mathrm{n}=21$ resp. 70 tjärnar, $\mathrm{P}=0,07$, tvåsidigt). Däremot fanns ingen signifikant skillnad vad gäller andelen ungkullar med två "stora" ungar, 25\% resp. 32\% (Mann-Whitney U-test, $\mathrm{n}=21$ resp. 63 tjärnar, $\mathrm{P}=0,77$, tvåsidigt).

Det är således under ruvningsstadiet som eventu- ella fördelar med att häcka vid en tjärn med genomströmmande vatten ger utslag. Möjligen blir vattenståndsvariationerna i samband med regn, och därmed risken för översvämmande bon, mindre i tjärnar med genomströmmande vatten. Men vi saknar uppgifter om vattenståndsvariationerna i enskilda tjärnar, för en mera säker slutsats.

\section{Häckningsframgången för smålomspar som utnyttjar olika fiskevatten}

15-20 klarvattenssjöar samt två vattendrag (Västerdalälven och Uvan) har använts som fiskevatten för det undersökta smålomsbeståndet. För sex sjöar (Bredsjön, Kappsjösystemet, Kvien, Nyckelhällsjön/Rönnhällsjön, Petsjön och Öjen) som nyttjats av fler än fem smålomspar, har vi jämfört procentandelen tjärnar med häckning och den genomsnittliga ungproduktionen per år och par (för sjöar och vattendrag som nyttjas av ett eller ett fåtal par blir precisionen i beräkningarna alltför grov för meningsfulla analyser). Primärdata redovisas i Appendix 5.

Det fanns en tendens till att den genomsnittliga andelen tjärnar med häckning i regel var högst för Kappsjösystement och Öjen (70 resp. 66\%) och lägst för sjösystemet Nyckelhällsjön/Rönnhällsjön (47\%) ("Kendall coefficient of concordance", $\mathrm{W}=0,31, \mathrm{~N}=6$ fiskesjöar, $\mathrm{k}=10$ år, $\mathrm{P}<0,01$, primärdata från Appendix 5). Däremot var det ingen motsvarande tendens till att ungproduktionen för smålomspar fiskande i vissa sjöar skiljde sig från par fiskande $i$ andra sjöar ( $W=0,10, N=6$ fiskesjöar, $\mathrm{k}=10$ år, ej sign., primärdata från Appendix 5). Andelen ungkullar med två "stora" ungar var genomgående lägre för par fiskande i Öjen och Bredsjön, jämfört med de övriga sjöarna (W=0,19, N=6 fiskesjöar, $\mathrm{k}=10$ år, $0,05<\mathrm{P}<0,10$, primärdata från Appendix 5),

Det fanns ingen samvariation mellan åren mellan de olika fiskesjöarna, vare sig vad gäller andelen tjärnar med häckning eller ungproduktionen $(\mathrm{W}=$ 0,20 resp. $0,25, N=10$ år, $\mathrm{k}=6$ fiskesjöar, ej sign., primärdata från Appendix 5). Däremot var samvariationen mellan åren vad gäller procentandelen ungkullar med två "stora" ungar för par fiskande i de olika sjöarna signifikant $(\mathrm{W}=0,32, \mathrm{~N}=10$ år, $\mathrm{k}=6$ fiskesjöar, $0,02<\mathrm{P}<0,05$, primärdata från Appendix 5). Detta tyder på att föräldrafåglarnas förmåga att finna bytesfisk för ungarna varierat på ett likartad sätt i de olika sjöarna, och att det kan finnas bakomliggande, regionalt verkande faktorer som påverkat tillgången på bytesfisk på ett likartat sätt i olika vatten. 
Sammanfattning avfågelskyddsaspekterför smålom

Vi bedömer att ungproduktionen varit tillräcklig för att bibehålla beståndet storlek på en oförändrad nivå inom vårt studieområde åren 1991-2000. Men en negativ trend i ungproduktionen kan inte uteslutas, även om tio år kan vara för kort tid för mer definitiva slutsatser; med tanke på att smålommen är en långlivad fågel och att variationerna mellan åren i ungproduktionen kan vara avsevärd, med enstaka "goda" år och flera "dåliga" år med låg ungproduktion däremellan (t.ex. Eriksson \& Lindberg 1997). Under år med tidig häckningsstart är i regel kläckningsframgången såväl som ungarnas överlevnad till flygg ålder högre.

Det är svårt att identifiera enstaka faktorer som varit av avgörande betydelse för häckningsframgången. Det finns indikationer på att den varit högre i häckningstjärnar med lämpliga boöar, och att predation är en viktig orsak till misslyckade häckningar.

Indikationen på en nedåtgående trend i ungproduktionen är ett motiv för en fortsatt övervakning av smålommens häckningsframgång. Den negativa trenden vad gäller procentandelen ungkullar med två "stora" ungar (Figur 8) kan vara en varningssignal för försämrade fiskeförhållanden i fiskevattnen och ökade svårigheter för smålomsföräldrarna att mata sina ungar. Detta kan i sin tur vara en indikation på mer generella förändringar i fiskbeståndens sammansättning, som därför bör ges uppmärksamhet i framtida miljöövervakning och forskning. Sedan tidigare vet man att smålommen i stor utsträckning koncentrerar sitt födosök till sjöar med goda bestånd av laxartad fisk (t.ex. Rosenius 1942, Andersson 1988, Eriksson \& Sundberg 1991, Borgström 1996); vanligtvis siklöja Coregonus albula, men i norrländska kraftverksmagasin även småvuxen sik Coregonus sp. (Bildström 2000) och i sydvästra Sverige också sjöar med goda bestånd av mörtartad fisk (Erikson \& Sundberg 1991). Vidare får fisken inte vara för stor, eftersom ungarna har svårt för att hantera och svälja byten som är större än ungefär 20 cm (Norberg \& Norberg 1976, Eriksson m.fl. 1990). Eftersom dieten är koncentrerad till småvuxen laxoch mörtartad fisk, har smålommen bedömts vara mer sårbar än storlommen för förändringarna i fiskbestånden i försurningspåverkade sjöar (t. ex. Eriksson 1994).

Ruvande smålommar kan påträffas från början av maj till och med utgången av juli, och den senaste notering av en ruvande fågel gjordes den 8 augusti 1995. Om man bedömer att fritidsfiske eller annat friluftsliv kan störa de häckande smålommarna, bör således eventuella restriktioner i tillträde till häckningsområden (t.ex. genom att inrätta fågelskyddsområden) gälla åtminstone för perioden 15 april31 juli.

\section{Tack}

Flera personer har genom åren bidragit med smålomsobservationer. Följande har mer aktivt deltagit i inventeringarna: Janne Dahlén, Hans-Erik Eriksson, Börje Flygar, Lars Halvarsson, Harry Hedman, Bertil Helmersson, Birger Johansson, Bror-Erik Larsson, Åke Olsson och Sven-Erik Oscarsson. Mats Nordhag har hjälpt till med en del arealmätningar. David Okill, med mångårig erfarenhet av smålomsinventeringar på Shetlandsöarna, har faktagranskat den engelska texten. Börje Flygar har inspirerat till inventeringen genom ringmärkning av smålommar sedan början av 1970-talet. Under undersökningsperioden har han i det inventerade området ringmärkt 315 smålommar. Ekonomiska bidrag har erhållits ur Elis Wides fond och Alvins fond.

\section{Referenser}

Alison, R. M. 1976. Oldsquaw brood behavior. Bird Banding 47: $210-213$.

Andersson, M. 1988. Smålommen i Västmanland. Fåglar $i$ Västmanland 19: 85-93.

Arvidsson, B.L., Boström, U., Dahlén, B., De Jong, A., Kolmodin, U. \& Nilsson, S.G. 1992. The importance of mires as breeding habitat for wetland birds in Sweden. Ornis Svecica 2: 67-76.

Ball, I.J., Gilmer, D.S., Cowardin, L. \& Riechmann, J.H. 1975. Survival of wood duck and mallard broods in North-Central Minnesota. J. Wildl. Manage. 39: 776-780.

Beintema, A.J. 1992. (Mayfield, a must; exercises in calculation of nesting success.) Limosa 65: 155-162 (på holländska, sammanfattning på engelska).

Beintema, A.J. 1996. Inferring nest success from old records. Ibis 138: 568-570.

Bildström, L. 2000. Smålommarna i Sandforsdammen. Fåglar $i$ Västerbotten 25: 97-98.

Booth, C.J. 1982. Fledging success of some Red-throated Divers in Orkney. Scottish Birds 12: 33-38.

Borgström, E. 1993. Smålommen Gavia stellata som häckfågel i mellersta Värmland. Värmlandsornitologen 21: 44-49.

Borgström, E. 1996. Smålommen i Hagfors kommun 1995. Värmlandsornitologen 24: 45-50.

von Braun, C., Hessle, A.-C. \& Sjölander, S. 1968. Smålommens (Gavia stellata $\mathrm{L}$.) beteende under ungvårdnadstiden. Zoologisk Revy 30: 94-95.

Cramp, S. \& Simmons, K.E.L. 1977. The Birds of Western Palearctic, Vol. 1. Oxford University Press, Oxford.

Dahlén, B. 1997. Inventering av smålom i Malungs socken 1996. Fåglar i Dalarna 30: 3-10.

Dickson, L. 1992. The Red-throated Loon as an indicator of 
environmental quality. Canadian Wildlife Service Occassional Paper No. 73.

Dickson, L. 1993. Breeding biology of Red-throated Loons in the Canadian Beaufort Sea Region. Arctic 48: 1-7.

Douglas, S.D. \& Reimchen, T.E. 1988a. Habitat characteristics and population estimate of breeding Red-throated Loons, Gavia stellata, on the Queen Charlotte Islands, British Columbia. Canadian Field Naturalist 102: 679-684.

Douglas, S.D. \& Reimchen, T.E. 1988b. Reproductive phenology and early survivorship in Red-throated Loons, Gavia stellata. Canadian Field Naturalist 102: 701-704.

Dow, H. \& Fredga, S. 1983. Breeding and natal dispersal of the Goldeneye, Bucephala clangula. J. Anim. Ecol. 52: 681695.

Duncan, D.C. 1983. Extensive overland movement of Pintail, Anas acuta, brood and attempted predation by hawks. Canadian Field-Naturalist 97: 216-217.

Eberl, C. \& Picman, J. 1993. Effects of nest-site location on reproductive success of Red-throated Loon (Gavia stellata). Auk 110: 436-444.

Eriksson, M.O.G. 1978. Lake selection of Goldneye ducklings in relation to the abundance of food. Wildfowl 29: 81-85.

Eriksson, M.O.G. 1994. Susceptibility to freshwater acidification by two species of loon: Red-throated Loon (Gavia stellata) and Arctic Loon (Gavia arctica) in southwest Sweden. Hydrobiologia 279/280: 439-444.

Eriksson, M.O.G., Arvidsson, B. \& Johansson, I. 1988. Habitatkaraktärer hos häckningssjöar för smålom Gavia stellata i sydvästra Sverige. Vår Fågelvärld 47: 122-132.

Eriksson, M.O.G., Blomqvist, D., Hake, M. \& Johansson, O. 1990. Parental feeding in the Red-throated Diver Gavia stellata. Ibis 132: 1-13.

Eriksson, M.O.G. \& Johansson, I. 1997. Smålommen Gavia stellata i sydvästra Sverige - beståndsutveckling och häckningsframgång. Ornis Svecica 7: 1-10.

Eriksson, M.O.G., Johansson, I. \& Ahlgren, C-G. 1992. Levels of mercury in eggs of Red-throated Diver Gavia stellata and Black-throated Diver G. arctica in Southwest Sweden. Ornis Svecica 2: 29-36.

Eriksson, M.O.G. \& Lindberg, P. 1997. Storlom och smålom i sydvästra Sverige. Sid. 34-39 i Josefsson, K. \& Olsson, L. (red.) Miljötillståndet i Älvsborgs län - årsrapport från miljöövervakningen. Länsstyrelsen $i$ Älvsborgs län Rapport 1997:6.

Eriksson, M.O.G. \& Lindberg, P. 1998. Projekt Lom 1997. Sid. 71-75 i SOF 1998 Fågelåret 1997. Sveriges Ornitologiska Förening, Stockholm.

Eriksson, M.O.G. \& Lindberg, P. 2000a. Projekt Lom 1999. Sid. 35-39 i SOF 2000 Fågelåret 1999. Sveriges Ornitologiska Förening, Stockholm.

Eriksson, M.O.G. \& Lindberg, P. 2000b. Påverkar kanadagässen Branta canadensis häckningsresultatet för smålom Gavia stellata och storlom G. arctica? Ornis Svecica 10: 85-94.

Eriksson, M.O.G. \& Sundberg, P. 1991. The choice of fishing lakes by the Red-throated Diver Gavia stellata and Blackthroated Diver $G$. arctica during the breeding season in south-west Sweden. Bird Study 38: 135-144.

Forbes, L.S. 1993. Avian brood reduction and parent-offspring "conflict". American Naturalist 142: 82-117.

Gibbons, D.W., Bainbridge, I.P., Mudge, G.P., Tharme, A.P. \&
Ellis, P.M. 1997. The status and distribution of the Redthroated Diver Gavia stellata in Britain in 1994. Bird Study 44: 194-205.

Gomersall, C.H. 1986. Breeding performance of the redthroated diver Gavia stellata in Shetland. Holarctic Ecology 9: 277-284

Götmark, F., Neergaard, R. \& Åhlund, M. 1988. Storlommen i Fegen-Kalvsjön-Svansjöarna. Länsstyrelsen i Älvsborgs län 1988:8.

Götmark, F., Neergaard, R. \& Åhlund, M. 1989. Nesting ecology and management of the Arctic Loon in Sweden. J. Wildl. Manage. 53: 1025-1031.

Götmark, F., Neergaard, R. \& Åhlund, M. 1990. Predation of artificial and real Arctic Loon nests in Sweden. J. Wildl. Manage. 54: 429-432.

Harvey, P.H., Greenwood, P.J. \& Perrins, C.M. 1979. The role of dispersal in the great tit (Parus major): the causes, consequences and heritability of natal dispersal. J. Anim. Ecol.48: 123-142.

Johnson, D.H. 1979. Estimating nesting success: The Mayfield method and an alternative. Auk 96: 651-661.

Lehtonen, L. 1970. Zur Brutbiologie des Prachttauchers, Gavia a. arctica (L.). Ann. Zool. Fennici 7: 25-60.

Lindberg, P. 1968. Något som storlommens (Gavia arctica L.) och smålommens (Gavia stellata L.) ekologi. Zoologisk Revy 30: 83-88.

Lindberg, P. 1971. Lommar. Sveriges Natur Årsbok 62: 140145.

Lokki, J. \& Eklöf, K. 1984. Breeding success of the Redthroated Diver (Gavia stellata) in southern Finland. Ann. Zool. Fennici 21: 417-419.

Mayfield, H. 1961. Nesting success calculated from exposure. Wilson Bulletin 73: 255-261.

Mayfield, H. 1975. Suggestions for calculating nesting success. Wilson Bulletin 87: 456-466.

Merrie, T.D.H. 1978. Relationship between spatial distribution of breeding divers and the availability of fishing waters. Bird Study 25: 199-122.

Norberg, R.Å. \& Norberg, U.M. 1971. Take-off, landing and flight speed during fishing flights of Gavia stellata (Pont.). Ornis Scandinavica 2: 55-67.

Norberg, R.A. \& Norberg, U.M. 1976. Size of fish carried by flying Red-throated Divers Gavia stellata (Pont.) to nearly fledged young in nesting tarn. Ornis Fennica 53: 92-95.

Okill, J.D. 1992. Natal dispersal and breeding site fidelity of Red-throated Divers Gavia stellata in Shetland. Ringing \& Migration 13: 57-78.

Okill, J.D. \& Wanless, S. 1990. Breeding success and chick growth of Red-Throated Diver Gavia stellata in Shetland 1979-88. Ringing \& Migration 10: 26-30.

Reimchen, T.E. \& Douglas, S. 1984. Feeding schedule and daily food consumption in Red-throated Loons (Gavia stellata) over the prefledging period. Auk 101: 593-599.

Rosenius, P. 1942. Svenska fåglar och fågelbon, femte bandet. Gleerups, Lund.

Skyllberg, U., Lessman, J. \& Hansson, P. 1999 Häckningsmiljöns betydelse för häckningsframgången hos havsfiskande smålom Gavia stellata i Västerbotten. Ornis Svecica 9: 107-120.

SOF. 1990. Sveriges fåglar, 2:a upplagan. Sveriges Ornitologiska Förening, Stockholm. 


\section{Summary}

Breeding biology of the Red-throated Diver Gavia stellata in the core area of the Swedish population

A population of about 70 pairs of Red-throated Diver Gavia stellata was surveyed during a period of ten years, 1991-2000, within a $1820 \mathrm{~km}^{2}$ area dominated of coniferous forests and mires in Malung Municipality $\left(60^{\circ} 41^{\prime} \mathrm{N}, 13^{\circ} 43^{\prime} \mathrm{E}\right)$, Dalarna, Sweden (Figure 1). In the study area, Red-throated Divers breed in small tarns (most of them smaller than $1 \mathrm{ha}$ ) and forage in larger freshwater lakes up to $4.6 \mathrm{~km}$ from the breeding sites. Many of the fishing lakes are target for lime-treatment in order to counteract adverse effects on the fish stocks due to influence of air-borne acidifying pollutants.

A substantial proportion of the Swedish population of Red-throated Diver breed within a limited area in the south-central parts of the country. In Dalarna, Värmland and Västmanland, 370-440 pairs or approximately one third of the Swedish population of 1200-1400 pairs is found, according to assessments during the 1990's (Eriksson \& Lindberg 1998). Our study sites are located within this core area.

\section{Material and methods}

Percentage of inhabited tarns, production of young and breeding success.

We used the following criteria for describing breeding parameters. Stationary pair: A pair of Red-throated Divers recorded at least twice, with an interval of at least two weeks between two successive observations, at a potential breeding site during the breeding season. Breeding pair: Breeding indications exist, such as mating, nest, eggs, incubating bird and/or chicks. Successful breeding: Breeding with at least one "large" (half grown - fledged) chick. Replacement: We judged that a replacement clutch had been laid only when a failure of the first breeding attempt could be confirmed. Thus, the there is a risk that single breeding attempts detected late during the season erroneously have been classified as first clutches.

We used the following parameters for assessments of breeding success (primary data in Appendix 1). Percentage of tarns with breeding in relation to the number of tarns surveyed, in order to get an indication of the use of tarns ("number of tarns" refers to the number surveyed each year). Production of young, calculated as the mean number of "large" chicks per breeding pair. Breeding attempts not followed until chicks became "large", as well as attempts not detected until "large" chicks were recorded (without any previous record of mating, nest, eggs or incubation) were not included. Thus, the number of pairs used for these calculations is lower than the real number of breeding pairs for single years. Percentage of successful breeding attempts with two "large" chicks, in order to get an indication of the survival of chicks. These calculations also include breeding attempts not detected until after the chicks were hatched. Breeding success was assessed with the Mayfield method (Mayfield 1961, 1975, Johnson 1979, Beintema 1996). We split up the analyses in an assessment of hatching success, i.e. the probability that the clutch would hatch, and brood rearing success, i.e. the probability that at least one chick would survive until fledged age (primary data in Appendix 2). We also compared the probability of individual survival of chicks in broods with one and two chicks (primary data in Appendix 3).

\section{Start of incubation}

The date for start of incubation was assessed with the Mayfield method, setting this to the middle date between two successive observations (Beintema 1996 for details).

\section{Size and location of nests}

In 1991-1997, we collected the following data for the majority of nests. Size, i.e. largest and smallest inner diameter of the nest. Distance from inner edge of nest to water edge, following the "path" used by the nesting birds. Distance from breeding islet to mainland shore (i.e. solid ground).

\section{Characteristics of the breeding tarns}

For the various breeding tarns, we investigated the following parameters. The use by breeding Redthroated Divers, calculated as the percentage of years with breeding attempts in relation to the total number of years the tarn was surveyed. The average production of young, calculated as the mean number of "large" chicks per year. There was no case of more than one pair breeding at the same tarn.

The use of tarns and production of young were related to the following characteristics (primary data are summarized in Appendix 4). Surface area: In previous studies, small tarns $(<1$ ha) have been 
found to be more attractive or productive (e.g. in Shetland, Gomersall 1986, Okill \& Wanless 1990). But the tarns must not be too small to allow for takeoff and landing by adult birds (Norberg \& Norberg 1971). Distance to road, as an indicator on disturbance from human activities. Distance to foraging waters: In various studies, transport of fish from foraging waters to the breeding tarns has been assumed to be energy demanding and thus affect the breeding success for pairs at tarns located distantly from the fishing waters (e.g. Eberl \& Picman 1993, Eriksson \& Johansson 1997). Occurrence of suitable breeding islets: Nests on small islets have often been assumed to be less susceptible to predation or human disturbance (e.g. Lokki \& Eklöf 1984, Eriksson et al. 1988). Waterflowing through: Tarns with and without well defined inflow(s) and outlet were compared, assuming that they were differently affected of waterlevel fluctuations, e.g. after heavy rainfall.

\section{Comparisons between fishing lakes}

We investigated if any differences in breeding success might be related to conditions in the fishing lakes. Six fishing lakes, each of them used by at least five breeding pairs in various tarns, were compared with reference to the average percentage of inhabited tarns, mean number of "large" chick per pair and year, and the average percentage of broods with two "large" chicks.

\section{Results and discussion}

\section{Surveyed tarns and pairs}

Most of the approximately 680 tarns (up to 8 ha in size) in the study area were visited at least once during the study period, and 130-150 tarns were visited every year. Our study includes 95 of these tarns, i.e. those where breeding was confirmed at least once during 1991-2000. Of these 95 tarns, 6692 tarns were surveyed each year. 70 tarns (74\%) were surveyed during nine or ten years, and 91 of them $(96 \%)$ during at least five years (Table 1$)$. In no case was more than one stationary breeding pair recorded in a single tarn.

The number of surveyed pairs varied from 42 pairs in 1991 to 74 pairs in 1999, and it increased significantly during the study period (Spearman $\mathrm{r}_{\mathrm{s}}=0.73, \mathrm{n}=10$ years, $0.01<\mathrm{P}<0.025$, data from Appendix 1). We believe that this increase was a combined affect of more effective fieldwork and a real increase in population size.
On average, stationary or breeding pairs were recorded in approximately two thirds of the surveyed tarns. The percentage of tarns inhabited increased between 1991-1999 (Figure 2, Spearman $r_{s}=0.93$ and 0.80 , respectively for the percentage of tarns with stationary and breeding pairs, $\mathrm{n}=9$ years, $\mathrm{P}<0.01$ ), indicating a population increase. The increasing trend was, however, broken (temporarily?) in 2000, when the lowest percentage of inhabited tarns over the whole study period was recorded.

\section{Time of breeding start}

The start of incubation of first clutches was spread over a period of approximately $1 \frac{1}{2}$ months, from mid-May until end of June. Replacements were initiated from early June until mid-July (Table 2). But for approximately half the number of pairs, the initiation of first clutches was concentrated to a limited period of around ten days, however the timing for this period differed between years (Table 2). There was no indication of any relationship between the percentage of tarns with breeding pairs and median date for start of incubation (Spearman $r_{s}=-0.26, N=10$ years, N.S.). There may be a weak relationship between early start of incubation and high temperature in May (Spearman $r_{s}=-0.44, N=10$ years, N.S.), while influence from precipitation was not important (Spearman $\mathrm{r}_{\mathrm{s}}=0.24, \mathrm{~N}=10$ years, N.S.).

\section{Production of young and breeding success}

The average production was 0.76 "large" chicks per pair and year, with an indication of a decline during the study period (Figure 3). Thus, the production was on the same level as recorded for Central Sweden in 1994-99 (0.71 "large" chicks per pair and year), but lower than reported from southwestern and northern Sweden during the same period (Eriksson $\&$ Lindberg 2000a). The negative trend seems primarily to be related to a decreased percentage of successful breeding attempts with two chicks (Figure 8 ), while the trend concerning hatching success was less apparent (Spearman $r_{s}=-0.37, N=10$ years, N.S., data from Appendix 1).

With reference to other studies, we estimate that the average production of young in 1991-2000 was sufficient to maintain a stable population size. In Orkney, average production was 0.70 "large" chicks per pair and year in 1973-80 (13 pairs, Booth 1982), whereas it was much lower on Shetland averaging 0.44 "large" chicks per pair and year 1981-82 (91- 
100 pairs, Gomersall 1986). From the beginning of the 1980's until 1994, the size of the Red-throated Diver population on Shetland declined from around 700 pairs to 390 pairs, while the number on Orkney was stable at 90-100 pairs (Gibbons et al. 1994). For an increasing Red-throated Diver population in southern Finland, the average production was 1.15 "large" chicks per pair and year (1979-82, 17-32 pairs, Lokki \& Eklöf 1984).

There was an indication of a higher production of young in seasons with an on average early start of incubation (Figure 4). However, we did not find any tendency for a lower hatching success among late initiated breeding attempts within a single breeding seasons (in contrast to reports from Shetland, Gomersall 1986): Median date for start of incubation of first clutches did not differ between hatched and non-hatched clutches (Table 3, Wilcoxon signed ranks test, $\mathrm{P}=0.50$, two-tailed, N.S.).

On average, at least one egg hatched in $63 \%$ of all incubated clutches, and in $91 \%$ of all broods at least one chick survived until "large" (half grown-fledged) age (calculated with the Mayfield method, primary data in Appendices 1 and 2). The production of young was clearly linked to hatching success (Figure 5). On average over the whole study period, $58 \%$ of all initiated breeding attempts were successful in the sense that at least one "large" chick was produced.

There were significant relationships between higher production of young and high temperature as well as low precipitation during May (Figures 6 and 7). But there was no tendency for any relationship between temperature in June and the production of young (Spearman $\mathrm{r}_{\mathrm{s}}=-0.10, \mathrm{~N}=10$ years, N.S.), while there might have been a negative influence of high precipitation (Spearman $\mathrm{r}_{\mathrm{s}}=-0.41, \mathrm{~N}=10$ years, N.S.).

\section{Replacements}

On average, $15 \%$ of all failed first clutches were followed by a replacement clutch, but the percentage varied substantially between years from 4\% in 1998 to $50 \%$ in 1992 (primary data from Appendix 1). We did not find any indication of a relationship between the percentage of replacements and median date for the initiation of first clutches (Spearman $r_{s}=-0.30$, $\mathrm{N}=10$ years, N.S., primary data from Appendix 1 and Table 2).

The average production of young was lower among replacements than first clutches, 0.56 and 0.73 "large" chicks per pair and year, respectively, but the difference was not significant (Wilcoxon signed ranks test, $\mathrm{P}=0,27$, two-tailed, $\mathrm{N}=10$ years). The same result was recorded in Shetland 1981-83 (Gomersall 1986), although it was interpreted as an effect of an overall lower breeding success among clutches initiated late in the season. As mentioned above, we did not find any such a tendency in our material. There was no relationship between years concerning the percentage of replacement clutches and the mean number of "large" young per pair (Spearman $r_{s}=0.30, N=10$ years, N.S., data from Appendix 1).

Weather during May did not influence the occurrence of replacement clutches (Spearman $r_{s}=$ 0.04 and 0.25 , respectively, for comparisons of the percentage of replacements with temperature and precipitation, respectively, $\mathrm{N}=10$ years, N.S.). But replacement clutches were more frequent in years with low precipitation in June (Spearman $\mathrm{r}_{\mathrm{s}}=-0.47$, $\mathrm{N}=10$ years, $0.05<\mathrm{P}<0.10$ ).

Median date for start of incubation of first clutches that later failed and was followed by replacements was 27 May (median date for five years), compared to 2 June for first clutches that failed without being followed by replacements (the comparison only included 1991, 1992, 1994, 1996 and 1997, due to insufficient information for the other years, Wilcoxon signed ranks test, $\mathrm{P}=0.43$, two-tailed, N.S.). Hence, there was no "calendar effect" in respect to initiating a replacement clutch or not. However, replacements were more common when the first clutch failed during the first or second week of incubation, compared to when it occurred later. The average number of exposure days (according to the Mayfield method) was 13 days (mean for ten years) for failed first clutches followed by a replacement, compared to 19 days for failed first clutches not followed by any replacement (Wilcoxon signed ranks test, $\mathrm{P}=0.03$, two-tailed).

\section{Survival of chicks until fledging age}

The percentage of broods with two "large" chicks decreased over the study period (Figure 8). There was a clear relationship between the percentage of broods with two large chicks and the mean number of "large" chicks per pair (Figure 9), i.e. both nestling survival and hatching success (Figure 5) affected the total production of young. Furthermore, there was a significant relationship between median date for start of incubation of first clutches and the percentage of broods with two "large" chicks (Figure 10), i.e. survival was higher in seasons with an early start of breeding. But there was no indication of lower 
survival of chicks in late-hatched broods within each season. Median date for hatching of broods with and without loss of chicks during the period they were kept under observation did not differ (Table 4, Wilcoxon signed ranks test, $\mathrm{P}=0.49$, two-tailed, N.S.).

The percentage of broods where both chicks survived until "large" age was lower in seasons with high precipitation during June (Spearman $r_{s}=-0.54$, $\mathrm{N}=10$ years, $0.05<\mathrm{P}<0.10$, primary data from Appendix 1), while precipitation during July was of no importance (Spearman $r_{s}=-0.27, N=10$ years, N.S., primary data from Appendix 1). Temperature seemed to have no effect (Spearman $r_{s}=-0.26$ and 0.00 for June and July, respectively, $\mathrm{N}=10$ years, N.S., data from Appendix 1). Thus, it is during June, i.e. the first weeks after hatching, that the chicks are most susceptible to any adverse effects of rainy weather.

The individual probability for survival until fledging age was lower for chicks in "two-chicks" as compared to "one-chick" broods, $86 \%$ and $70 \%$ respectively (Figure 11, Wilcoxon signed ranks test, $\mathrm{P}=0.04$, two-tailed). Furthermore, the variation in chick survival between years was larger for "twochicks" compared to "one-chick" broods (Figure 11). At least in some years a single chick may substantially increase its probability for survival until fledging age if the other chick disappears. In most cases, we have no information on the reason for why chicks disappeared. However, based on other studies it is likely that differences between years in the survival of chicks are linked to feeding frequency (e.g. Reimchen \& Douglas 1984, Eriksson et al. 1990). Aggression between Red-throated Diver chicks has been reported in various studies, and when it occurs the smallest or weakest chick may die already a few days after hatching (e.g. von Braun et al.1998, Dickson 1992, 1993, Eberl \& Pickman 1993). Furthermore, the difference in weight between two half-grown chicks in the same brood may be as large as $10 \%$, and a single chick in a "one-chick" brood may weight almost as much as the largest chick in a "two-chicks" brood (as found in studies in Shetland, Okill \& Wanless 1990). These results conform with knowledge acquired from other birds species with asynchronous hatching (e.g. herons, raptors) where the first hatched chick has an advantage over the smaller, later hatched ones, in competition between siblings for food offered by the parents.

We do not exclude the possibility that the decreasing trend in the percentage of broods with two "large" chicks reflects a general impairment of the availability of prey fish in our study area.

\section{Overland movements between tarns}

We have confirmed seven cases when non-fledged Red-throated Diver chicks have moved overland between tarns, up to a maximum of $350 \mathrm{~m}$ (Table 5). In five cases, travels have been directed from smaller to larger tarns, i.e. contrary to what might have been expected with reference to the larger percentage of broods with two "large" chicks in small tarns (Table 10). But one incitement for moving to a larger tarn might be better conditions for take-off and landing for the parents, and possibly also for the young birds when learning how to fly. Twice, a chick was observed to have disappeared in connection with overland movements between tarns.

\section{Breeding success in relation to the size and location of nests.}

Nests where clutches hatched were approximately 1 $\mathrm{cm}$ larger in diameter (Table 6). This might be an indication of higher incubation success by largesized individuals, provided that large-sized individuals build larger nests and that nest size is related to size of the largest individual in the pair.

Distance between the nest and the water edge varied between 7 and $67 \mathrm{~cm}$, but did not differ with reference to hatching success (means $=22 \mathrm{~cm}$. and $21 \mathrm{~cm}$., respectively; Table 6). For nests on islets, there was a (non-significant) indication of larger mean distance to the mainland shore for hatched $(8.6$ $\mathrm{m})$ compared with for non-hatched $(6.1 \mathrm{~m})$ clutches (Table 6).

Nest site fidelity, and changes of nest sites and breeding tarns between breeding seasons

There was a clear indication that a limited number of tarns was used for the majority of breeding attempts. 40 tarns (42\%) were used during at least $75 \%$ of the seasons they were surveyed. The remaining ones were used more sporadically, and 16 of them (17\%) less than $25 \%$ of the years they were surveyed (Figure 12). The distribution of tarns with reference to the frequency they were used by breeding Redthroated Divers was significantly different from expected by chance $\left(\mathrm{Chi}^{2}=15.69, \mathrm{df}=3, \mathrm{P}<0.01\right.$, two-tailed). The results indicate a high degree of nest fidelity, in accordance with previous studies on Shetland (Okill 1992).

In agreement to what is known for many other bird species, we found a tendency to shift to a new nest sites after a failure. Within tarns, on average $64 \%$ of all breeding attempts that were successful until 
hatching were followed by breeding at the same location the following year, compared to $47 \%$ for breeding attempts that failed during incubation. But the tendency to shift to another location at the same tarn after a failure varied substantially between seasons and could only be confirmed with statistical significance for one year (Table 7). Considering the whole study period, a higher percentage of shifts to a new location during the following season was recorded for seven out of nine pair-wise comparisons between two successive years (Table 7; sign test: $\mathrm{N}=9$ years, $\mathrm{P}=0.18$, two-tailed).

There was a stronger pattern to abandon a tarn after a breeding failure. On average $85 \%$ of all pairs that bred successfully in one year were found at the same tarn the following year, compared to $66 \%$ of the cases when breeding failed. This tendency was recorded for all pair-wise comparisons between two successive years (Table 8; sign test: $\mathrm{N}=9$ years, $\mathrm{P}=0.04$, twotailed). But again, also this tendency varied between years (Table 8). The increasing tendency to abandon a tarn after a breeding failure is in accordance with previous results for Red-throated Divers in e.g. Canada and on Shetland (Gomersall 1986, Dickson 1993).

\section{Reasons for breeding failures}

In most cases, it is difficult to confirm the reason for a breeding failure, and for more than $50 \%$ of the breeding failures we had no indication of what caused the failure (Table 9). Furthermore, some potential reasons, such as flooding, may be more easily confirmed than e.g. predation or abandoning after human disturbance.

Predation was the most frequently assumed reason for failure (Table 9). In most cases, these judgements were based on findings of egg shells or tracks from potential predators in close vicinity to the nest. We recorded indication of predation on eggs by Red Fox Vulpes vulpes, Raven Corvus corax, Crane Grus grus and larids. Also in previous studies of Redthroated Divers in North America (e.g. Eberl \& Picman 1993, Dickson 1993) as well as in Sweden (Skyllberg et al. 1999), investigators have judged predation to be a main reason for failures. But human disturbance and predation can be difficult to separate, as the risk for predation my increase if the incubating bird is forced to leave the nest (as has been shown for the Black-throated Diver Gavia arctica, Götmark et al. 1988, 1990).

Flooded nests. This has been confirmed in three cases only. Presumably, the Red-throated Diver is less susceptible to water-level fluctuations than the
Black-throated Diver, as the quagmire shores where the nests often are located, to some extent float with the water-level fluctuations.

Disturbance by Canada Geese. In nine cases, disturbance by Canada Geese Branta canadensis were judged to be the reason failure. Thus, even if the expansion of Canada Geese does not seem to be any threat to the Red-throated Diver population on regional or national scales (Eriksson \& Lindberg 2000b), single pairs may suffer.

Human disturbance. In five cases, we judged that human disturbance (anglers etc.) contributed to breeding failures, although this factor is difficult to separate from predation (see above).

Floating nesting islet. In two cases, we noted that breeding attempts failed when the breeding islet had broken adrift. However, there are also cases when Red-throated Divers successfully completed breeding on drifting islets.

Dead parents. We have too limited information to evaluate to what extent breeding failures can be linked to the death of parents. In three cases, breeding failures were linked to the finding of a dead adult. In one case, an incubating bird had been attacked by a raptor, presumably Goshawk Accipiter gentilis or Eagle Owl Bubo bubo, while the cause of death has not been confirmed for the two other individuals. In general, it is likely that disease and starvation contribute to an impaired physical condition, which in turn may make the birds more susceptible to predation.

Mortality among the chicks. Among divers, normally both eggs hatch but often one chick disappears soon after hatching (see above). In most cases when loss of chicks were confirmed, there was no indication of the cause of death. In three cases, however, predation by Pike Esox lucius has been assumed. Dead chicks have been found at six occasions, which indicate that starvation or disease may be the cause in some cases. Most of the dead chicks were small to half grown, although one of them was almost fledged.

\section{Breeding in relation to characteristics of the breeding tarns}

We found a weak but significant relationship between the percentage of years with breeding and the average production of young in various tarns $\left(\right.$ Spearman $\mathrm{r}_{\mathrm{s}}=$ $0.25, \mathrm{~N}=91$ tarns, $\mathrm{P}=0.009$, data from Appendix 4). This result indicates the possibility of one or several common factors affecting the use of tarns as well as the breeding success. 
Surface area of tarns. The main part of the breeding tarns were smaller than 1.0 ha (Figure 12), and the largest tarn used for breeding was $8.2 \mathrm{ha}$. We found no indication of any relationship between surface area and the frequency tarns were used for breeding (Table 10). But there was a weak but significant relationship between increasing surface area and lower percentage of broods with two "large" chicks, although this was not reflected in any relationship between surface area and the mean number of "large" young per pair (Table 10). The result is in accordance with a previous study in southwestern Sweden, were no relationship between surface area (0.5-7.0 ha) and the production of young was found (Eriksson \& Johansson 1997). On Shetland, however, small tarns were more attractive for breeding Red-throated Divers and the hatching success higher in small tarns. These findings were linked to lower disturbance from anglers and more stable water-level (Gomersall 1986, Okill \& Wanless 1990).

Distance to road. We did not find any indication that distance to roads affected breeding frequency or the production of young (Table 10). Thus, human disturbance, to the extent this is linked to the vicinity of roads, seemed not to affect breeding success. Furthermore, the decline of the Red-throated Diver population in southwestern Sweden during the middle of the 20th century, could not be related to the location of tarns in relation to roads or buildings (Eriksson et al. 1988). Moreover, neither on Shetland was there any link between low breeding success and distance to roads (Gomersall 1986).

Angling regularly occurred only at two tarns (Nos. 75 and 100, Appendix 4), and the low breeding frequency (nesting only in two out of ten years) at one of them might be related to disturbance. Angling has only been recorded more occasionally at the other tarns.

Distance to fishing lakes. The majority of the breeding tarns were located at a distance of less than $1 \mathrm{~km}$ from the closest foraging sites (Figure 14), and the most distant tarns were located $4.6 \mathrm{~km}$ from the fishing lake. There was no indication that distance to fishing lakes affected either the frequency by which the tarns were used for breeding or the production of young (Table 10). However, the percentage of broods with two "large" chicks was lower in tarns located more distantly from the fishing lakes (Table 10).

In southwestern Sweden, a relationship between higher breeding success and closer distance to fishing lakes was recorded in a study of 19 tarns located $0.7-13.1 \mathrm{~km}$ from the nearest fishing lake (Eriksson \& Johansson 1997), i.e. a wider range than in the present study. From a Canadian study (Eberl \& Picman 1993), it was concluded that the hatching success was not related to distance to foraging waters, but there was a threshold value at approximately 9 $\mathrm{km}$ beyond which feeding frequency of chicks decreased. In Scotland (Merrie 1978) and Canada (Douglas \& Reimchen 1988a), it has been found that Red-throated Divers seldom breed more than 8-9 $\mathrm{km}$ from the fishing waters.

Thus, all the breeding tarns in our study were located so close to fishing waters that no adverse effect was to be expected. We believe that this also may apply to other studies were no indication of any relationship between distance to fishing sites and breeding success has been found.

Occurrence of suitable breeding islets. We did not find any indication that tarns with suitable breeding islets were more attractive for breeding Red-throated Divers. The average percentage of years with breeding was $63 \%$ and $56 \%$, respectively, for tarns with and without islets (Mann-Whitney U test, $\mathrm{n}=83$ and 12 tarns, $\mathrm{P}=0.44$, two-tailed). The production of young was somewhat (non-significantly) higher at tarns with islets, 0.71 and 0.61 "large" chicks per pair and year, respectively (Mann-Whitney U test, $\mathrm{n}=79$ and 12 tarns, $\mathrm{P}=0.28$, two-tailed). The percentage of broods with two "large" chicks did not differ for tarns with and without islets, 30\% and 33\% respectively (Mann-Whitney $\mathrm{U}$ test, $\mathrm{n}=73$ and 11 tarns, $\mathrm{P}=0.84$, two-tailed).

In southern Finland and in Canada, a higher breeding success was noted for Red-throated Diver pairs breeding on islets (Lokki \& Eklöf 1984, Douglas \& Reimchen 1988b). On Shetland, however, there was no indication of higher breeding success for pairs on islets (Gomersall 1986), but this might have been related to different predation pressures with a dominance of birds on Shetland (e.g. Great Blackbacked Gull Larus marinus, Arctic Skua Stercorarius parasiticus and Great Skua Stercorarius skua; Gomersall 1986). Nest location on islets may be advantageous for protection against terrestrial mammal predators, but be less important when birds are the dominating predators.

Water flow-through. We found an indication that tarns with flowing-through water might have been more attractive for breeding Red-throated Divers. The average percentage of years with breeding was $69 \%$ versus $59 \%$ (Mann-Whitney $U$ test, $n=23$ and 72 tarns, $\mathrm{P}=0.13$, two-tailed). Also, the production of young tended to be higher at tarns with flowingthrough water, 0.81 and 0.66 "large" young per pair and year, respectively (Mann-Whitney U test, $n=21$ 
and 70 tarns, $\mathrm{P}=0.07$, two-tailed). But there was no significant difference in the percentage of broods with two "large" chicks, $25 \%$ and $32 \%$, respectively (Mann-Whitney U test, $\mathrm{n}=21$ and 63 tarns, $\mathrm{P}=0.77$, two-tailed). We speculate that fluctuations in water level, e.g. after heavy rains, may be less pronounced in tarns with flowing-through water.

\section{Comparison of breeding success of pairs using diffe- rent fishing lakes}

15-20 freshwater lakes and two water courses were confirmed as foraging sites for the Red-throated Diver population under study. For six fishing lakes, each of them used by at least five different pairs, we compared the average percentage of tarns with breeding, the production of young per pair and year and the average percentage of broods with two "large" chicks (primary data in Appendix 5).

There was no covariance between years, either for the average percentage of tarns with breeding or the production of young (Kendall coefficient of concordance $\mathrm{W}=0.20$ and 0.25 , respectively $\mathrm{N}=10$ years, $\mathrm{k}=6$ fishing lakes, N.S. primary data from Appendix 5). But there was a significant covariance between years in the percentage of broods with two "large" chicks for pairs fishing at the different lakes ( $\mathrm{W}=0.32, \mathrm{~N}=10$ years, $\mathrm{k}=6$ fishing lakes, $0.02<\mathrm{P}<0.05$, primary data from Appendix 5). This result indicates that conditions for foraging varied in a similar way in different fishing lakes, and that a common factor acting on the region level affected the availability of prey fish.

\section{Concluding remarks}

In our study area, the production of young was enough to maintain a stable population size. But the indication of a negative trend at the end of the study period leads to some concern. The Red-throated Diver is a long-lived bird, and from previous monitoring we know that variations between years may be large, with single "good" years interspaced by several years with low production (e.g. Eriksson \& Lindberg 1997). We found that hatching success, as well as the survival of chicks until fledging age, were higher in seasons with an early breeding start.

It was difficult to identify single factors of decisive importance for breeding success. We found indications of higher breeding success at tarns with suitable breeding islets, and that predation was a main reason for breeding failures.

The indication of a decreasing trend in the production of young is an incitement for continued monitoring of the breeding success of Red-throated Divers in South-Central Sweden. The negative trend in the percentage of broods with two "large" chicks (Figure 8) may be an "early warning" of impaired foraging conditions and increased difficulties for the parents to feed the chicks. Thus, any link to changed foraging conditions needs to be more closely investigated. Red-throated Divers forage to a large extent in lakes with abundant stocks of small-sized salmonid fish such as various Coregonus species (e.g. Rosenius 1942, Andersson 1988, Eriksson \& Sundberg 1991, Borgström 1996, Bildström 2000), and in southern Sweden also cyprinid fish (Eriksson \& Sundberg 1991). Furthermore, the fish must not be too large for the chicks to handle and swallow (i.e. $<20 \mathrm{~cm}$; Norberg \& Norberg 1976, Eriksson et al. 1990). Because the diet is restricted to small-sized salmonid and cyprinid fish, the Red-throated Diver has been judged to be more susceptible than the Black-throated Diver for the ecological changes in freshwater lakes affected by acidification (e.g. Eriksson 1994).

Incubating Red-throated Divers can be found from early May until the end of July. In cases were human disturbance from anglers and other kinds of out-door recreation is to be kept under control, any restrictions should be valid at least for the period 15 April - 31 July. 
Appendix 1. Primärdata med avseende på antalet undersökta tjärnar, antal par, häckningsframgång och väderleksförhållanden. $\mathrm{N}=$ antal par.

Primary data for the number of investigated tarns, number of pairs, breeding success and weather conditions. $N$ $=$ number of pairs.

\begin{tabular}{|c|c|c|c|c|c|c|c|c|c|c|c|}
\hline & 1991 & 1992 & 1993 & 1994 & 1995 & 1996 & 1997 & 1998 & 1999 & 2000 & $\begin{array}{l}\text { Medel } \\
\text { Mean }\end{array}$ \\
\hline \multicolumn{12}{|l|}{ Undersökta tjärnar Surveyed tarns } \\
\hline Antal undersökta Number surveyed & 66 & 78 & 80 & 85 & 86 & 91 & 90 & 88 & 91 & 92 & \\
\hline Antal (\%) tjärnar med stationära par & 42 & 48 & 53 & 59 & 61 & 62 & 66 & 64 & 67 & 54 & \\
\hline Number $(\%)$ with stationary pairs & $64 \%$ & $62 \%$ & $66 \%$ & $69 \%$ & $71 \%$ & $68 \%$ & $73 \%$ & $73 \%$ & $74 \%$ & $59 \%$ & $68 \%$ \\
\hline Antal (\%) med fastställd häckning & 39 & 43 & 49 & 59 & 53 & 56 & 56 & 59 & 64 & 44 & \\
\hline Number $(\%)$ with breeding confirmed & $59 \%$ & $55 \%$ & $61 \%$ & $69 \%$ & $62 \%$ & $62 \%$ & $62 \%$ & $67 \%$ & $70 \%$ & $48 \%$ & $60 \%$ \\
\hline \multicolumn{12}{|l|}{ Ungproduktion Production of chicks } \\
\hline "Stora" ungar per stationärt par & 0,66 & 1,00 & 0,98 & 0,85 & 0,54 & 0,48 & 0,51 & 0,70 & 0,43 & 0,69 & \\
\hline "Large" chicks per stationary pair & $\mathrm{n}=35$ & $\mathrm{n}=38$ & $\mathrm{n}=52$ & $\mathrm{n}=59$ & $\mathrm{n}=57$ & $\mathrm{n}=62$ & $\mathrm{n}=63$ & $\mathrm{n}=65$ & $\mathrm{n}=67$ & $\mathrm{n}=51$ & \\
\hline "Stora" ungar per häckande par & 0,69 & 1,15 & 1,06 & 0,84 & 0,63 & 0,54 & 0,60 & 0,81 & 0,73 & 0,53 & 0,76 \\
\hline "Large" chicks per breeding pair & $\mathrm{n}=29$ & $\mathrm{n}=33$ & $\mathrm{n}=47$ & $\mathrm{n}=58$ & $\mathrm{n}=49$ & $\mathrm{n}=56$ & $\mathrm{n}=53$ & $\mathrm{n}=58$ & $\mathrm{n}=64$ & $\mathrm{n}=40$ & \\
\hline \% ungkullar med två "stora" ungar & $32 \%$ & $50 \%$ & $58 \%$ & $39 \%$ & $11 \%$ & $20 \%$ & $29 \%$ & $35 \%$ & $27 \%$ & $4 \%$ & $31 \%$ \\
\hline$\%$ broods with two "large" chicks & $\mathrm{n}=25$ & $\mathrm{n}=28$ & $\mathrm{n}=33$ & $\mathrm{n}=36$ & $\mathrm{n}=28$ & $\mathrm{n}=25$ & $\mathrm{n}=28$ & $\mathrm{n}=37$ & $\mathrm{n}=37$ & $\mathrm{n}=25$ & \\
\hline \multicolumn{12}{|l|}{ Häckningsframgång Breeding success } \\
\hline Kläckningsframgång (Mayfield, App. 2) & 0,60 & 0,82 & 0,65 & 0,69 & 0,67 & 0,4 & 0,51 & 0,73 & 0,60 & 0,54 & 0,63 \\
\hline Hatching success (Mayfield, App. 2) & & & & & & & & & & & \\
\hline Ungvårdnadsframgång (Mayfield, App. 2) & 0,93 & 0,96 & 0,93 & 0,93 & 0,80 & 0,93 & 0,86 & 0,80 & 0,96 & 0,96 & 0,91 \\
\hline Brood rearing success (Mayfield, App. 2) & & & & & & & & & & & \\
\hline Häckningsframgång (Mayfield, App. 2) & 0,56 & 0,79 & 0,61 & 0,64 & 0,54 & 0,46 & 0,44 & 0,58 & 0,58 & 0,52 & 0,58 \\
\hline \multicolumn{12}{|l|}{ Breeding success (Mayfield, App. 2) } \\
\hline \multicolumn{12}{|l|}{ Individ. Ungöverlevnad (Mayfield, App.3) } \\
\hline \multicolumn{12}{|l|}{ Individual chick survival (Mayfield, App. 3) } \\
\hline Kullar med en unge One-chick broods & 0,83 & 1,00 & 0,93 & 0,80 & 0,80 & 0,89 & 0,80 & 0,74 & 0,93 & 0,89 & 0,86 \\
\hline Kullar med två ungar Two-chicks broods & 0,86 & 0,77 & 0,93 & 0,83 & 0,48 & 0,80 & 0,66 & 0,83 & 0,74 & 0,46 & 0,74 \\
\hline \multicolumn{12}{|l|}{ Omhäckningar Replacements } \\
\hline Misslyckade första Failed 1st clutches & 14 & 10 & 17 & 25 & 22 & 32 & 29 & 25 & 28 & 18 & \\
\hline Omhäckningar Replacements & 2 & 5 & 1 & 4 & 3 & 3 & 6 & 3 & 1 & 1 & \\
\hline$\%$ omhäckningar $\%$ replacements & $14 \%$ & $50 \%$ & $6 \%$ & $16 \%$ & $14 \%$ & $9 \%$ & $21 \%$ & $12 \%$ & $4 \%$ & $6 \%$ & $15 \%$ \\
\hline "Stora" ungar per par, 1:a häckningar & 0,69 & 1,09 & 1,02 & 0,81 & 0,61 & 0,52 & 0,57 & 0,78 & 0,63 & 0,58 & 0,73 \\
\hline "Large" chicks per pair, 1 st clutches & $\mathrm{n}=29$ & $n=33$ & $\mathrm{n}=47$ & $\mathrm{n}=58$ & $\mathrm{n}=49$ & $\mathrm{n}=56$ & $\mathrm{n}=53$ & $\mathrm{n}=58$ & $\mathrm{n}=64$ & $\mathrm{n}=40$ & \\
\hline "Stora" ungar per par, omhäckningar & 0,00 & 0,40 & 2,00 & 0,50 & 0,33 & 0,33 & 0,33 & 0,67 & 1,00 & 0,00 & 0,56 \\
\hline "Large" chicks per pair, replacements & $\mathrm{n}=2$ & $\mathrm{n}=5$ & $\mathrm{n}=1$ & $\mathrm{n}=4$ & $\mathrm{n}=3$ & $\mathrm{n}=3$ & $\mathrm{n}=6$ & $\mathrm{n}=3$ & $\mathrm{n}=1$ & $\mathrm{n}=1$ & \\
\hline
\end{tabular}

Väderförhållanden Weather

Dygnsmedeltemperatur, ${ }^{\circ} \mathrm{C}$, i Malung

Daily mean temperature, ${ }^{\circ} \mathrm{C}$, in Malung

- Maj May

- Juni June

- Juli July

$9,6 \quad 14,7 \quad 10,3$

Nederbörd, mm, i Malung

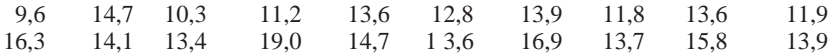

Precipitation, $\mathrm{mm}$, in Malung

- Maj May

- Juni June

$14,1 \quad 13,4$

8,2
11,2
19,0

$7,1 \quad 5,8$

$14,7 \quad 13,6$

$\begin{array}{rrrr}7,1 & 9,4 & 7,4 & 10,2 \\ 13,9 & 11,8 & 13,6 & 11,9 \\ 16,9 & 13,7 & 15,8 & 13,9\end{array}$

- Juli July

$\begin{array}{rr}18 & 29 \\ 127 & 12 \\ 48 & 70\end{array}$

$\begin{array}{rrrr}50 & 11 & 75 & 75 \\ 65 & 43 & 128 & 72 \\ 92 & 61 & 81 & 119\end{array}$

$\begin{array}{rrrr}172 & 29 & 39 & 107 \\ 47 & 107 & 114 & 94 \\ 35 & 86 & 64 & 133\end{array}$


Appendix 2. Primärdata för beräkning av häckningsframgång, enligt Mayfield-metoden. $\mathrm{N}=$ antal par, $\mathrm{a}=$ antal exponeringsdagar, $\mathrm{b}=$ antal misslyckade kullar, $\mathrm{S}$ = daglig överlevnad, beräknad enligt Beintema (1996), $\mathrm{S}^{\mathrm{L}}=$ häckningsframgång $(\mathrm{L}=$ ruvningsperiod 28 dagar, respektive period från kläckning tills ungarna blivit flygga 38 dagar; Gomerall (1986)).

\begin{tabular}{lll}
\hline Ruvning & Ungvårdnad & Totalt \\
Incubation & Chick rearing & Total \\
\hline
\end{tabular}

\begin{tabular}{lccc}
\hline 1991 & & & \\
$\mathrm{~N}$ & 28 & 37 & \\
$\mathrm{a}$ & 550 & 1169 & \\
$\mathrm{~b}$ & 10 & 2 & \\
$\mathrm{~S}$ & 0,982 & 0,998 & \\
$\mathrm{~S}^{\mathrm{L}}$ & 0,601 & 0,927 & 0,557 \\
\hline
\end{tabular}

\begin{tabular}{lccc}
\hline 1992 & & & \\
$\mathrm{~N}$ & 37 & 33 & \\
$\mathrm{a}$ & 1021 & 819 & \\
$\mathrm{~b}$ & 7 & 1 & \\
$\mathrm{~S}$ & 0,993 & 0,999 & \\
$\mathrm{~S}^{\mathrm{L}}$ & 0,821 & 0,963 & 0,791 \\
\hline
\end{tabular}

\section{3}

\begin{tabular}{lccc}
$\mathrm{N}$ & 44 & 35 & \\
$\mathrm{a}$ & 832 & 1212 & \\
$\mathrm{~b}$ & 13 & 2 & \\
$\mathrm{~S}$ & 0,986 & 0,998 & \\
$\mathrm{~S}^{\mathrm{L}}$ & 0,654 & 0,927 & 0,606 \\
\hline
\end{tabular}

\section{4}

\begin{tabular}{lccc}
$\mathrm{N}$ & 55 & 39 & \\
$\mathrm{a}$ & 1271 & 1377 & \\
$\mathrm{~b}$ & 17 & 3 & \\
$\mathrm{~S}$ & 0,987 & 0,998 & \\
$\mathrm{~S}^{\mathrm{L}}$ & 0,693 & 0,927 & 0,642 \\
1995 & & & \\
\hline
\end{tabular}

\begin{tabular}{lccc}
\hline $\mathrm{N}$ & 45 & 33 & \\
$\mathrm{a}$ & 873 & 1064 & \\
$\mathrm{~b}$ & 12 & 6 & \\
$\mathrm{~S}$ & 0,986 & 0,994 & \\
$\mathrm{~S}^{\mathrm{L}}$ & 0,674 & 0,796 & 0,536 \\
\hline
\end{tabular}

Primary data for calculation of breeding success with the Mayfield method. $N=$ Number of pairs, $a=$ Number of exposure days, $b=$ Number of failed clutches or broods, $S=$ Daily suvival, calculated according to Beintema (1996), $S^{L}=$ Hatching or fledging success $(L$ $=$ incubation period 28 days, and fledging period 38 days, respectively; Gomersall (1986)).

\begin{tabular}{|c|c|c|c|}
\hline & $\begin{array}{l}\text { Ruvning } \\
\text { Incubation }\end{array}$ & $\begin{array}{l}\text { Ungvårdnad } \\
\text { Chick rearing }\end{array}$ & $\begin{array}{l}\text { Totalt } \\
\text { Total }\end{array}$ \\
\hline \multicolumn{4}{|l|}{1996} \\
\hline $\mathrm{N}$ & 50 & 26 & \\
\hline $\mathrm{a}$ & 934 & 955 & \\
\hline b & 24 & 2 & \\
\hline S & 0,975 & 0,998 & \\
\hline $\mathrm{S}^{\mathrm{L}}$ & 0,492 & 0,927 & 0,456 \\
\hline \multicolumn{4}{|l|}{1997} \\
\hline $\mathrm{N}$ & 45 & 30 & \\
\hline $\mathrm{a}$ & 863 & 1011 & \\
\hline b & 18 & 4 & \\
\hline$S$ & 0,980 & 0,996 & \\
\hline $\mathrm{S}^{\mathrm{L}}$ & 0,509 & 0,859 & 0,437 \\
\hline \multicolumn{4}{|l|}{1998} \\
\hline $\mathrm{N}$ & 51 & 45 & \\
\hline $\mathrm{a}$ & 1046 & 1479 & \\
\hline b & 12 & 9 & \\
\hline $\mathrm{S}$ & 0,989 & 0,994 & \\
\hline $\mathrm{S}^{\mathrm{L}}$ & 0,734 & 0,796 & 0,584 \\
\hline \multicolumn{4}{|l|}{1999} \\
\hline $\mathrm{N}$ & 53 & 38 & \\
\hline $\mathrm{a}$ & 770 & 1419 & \\
\hline b & 14 & 1 & \\
\hline S & 0,982 & 0,999 & \\
\hline $\mathrm{S}^{\mathrm{L}}$ & 0,601 & 0,963 & 0,578 \\
\hline \multicolumn{4}{|l|}{2000} \\
\hline $\mathrm{N}$ & 29 & 28 & \\
\hline $\mathrm{a}$ & 610 & 1525 & \\
\hline b & 14 & 2 & \\
\hline S & 0,978 & 0,999 & \\
\hline$S^{L}$ & 0,536 & 0,963 & 0,516 \\
\hline
\end{tabular}


Appendix 3. Primärdata för beräkning av individuell ungöverlevnad i kullar med en respektive två ungar, enligt Mayfield-metoden. $\mathrm{N}=$ antal ungar, $\mathrm{a}=$ antal exponeringsdagar, $\mathrm{b}=$ antal försvunna ungar, $\mathrm{S}=$ daglig överlevnad, beräknad enligt Beintema (1996), $\mathrm{S}^{\mathrm{L}}=$ Sannolikhet för överlevnad till flygg ålder $(\mathrm{L}=$ period från kläckning tills ungarna blivit flygga, 38 dagar; Gomersall (1986)).

\begin{tabular}{|c|c|c|c|c|c|}
\hline & $\begin{array}{l}\text { Kullar med en unge } \\
\text { One-chick broods }\end{array}$ & $\begin{array}{l}\text { Kullar med två ungar } \\
\text { Two-chicks broods }\end{array}$ & & $\begin{array}{l}\text { Kullar med en unge } \\
\text { One-chick broods }\end{array}$ & $\begin{array}{l}\text { Kullar med två ungar } \\
\text { Two-chicks broods }\end{array}$ \\
\hline 1991 & & & 1996 & & \\
\hline $\mathrm{N}$ & 18 & 18 & $\mathrm{~N}$ & 20 & 20 \\
\hline $\mathrm{a}$ & 394 & 450 & $\mathrm{a}$ & 637 & 636 \\
\hline b & 2 & 2 & $\mathrm{~b}$ & 2 & 4 \\
\hline S & 0,995 & 0,996 & $\mathrm{~S}$ & 0,997 & 0,994 \\
\hline$S^{\mathrm{L}}$ & 0,827 & 0,859 & $\mathrm{~S}^{\mathrm{L}}$ & 0,892 & 0,796 \\
\hline 1992 & & & 1997 & & \\
\hline $\mathrm{N}$ & 19 & 38 & $\mathrm{~N}$ & 20 & 34 \\
\hline $\mathrm{a}$ & 316 & 1006 & $\mathrm{a}$ & 511 & 1000 \\
\hline b & 0 & 7 & $\mathrm{~b}$ & 3 & 11 \\
\hline S & 1,00 & 0,993 & $S$ & 0,994 & 0,989 \\
\hline $\mathrm{S}^{\mathrm{L}}$ & 1,00 & 0,767 & $\mathrm{~S}^{\mathrm{L}}$ & 0,796 & 0,657 \\
\hline 1993 & & & 1998 & & \\
\hline $\mathrm{N}$ & 15 & 48 & $\mathrm{~N}$ & 31 & 36 \\
\hline $\mathrm{a}$ & 408 & 1608 & $\mathrm{a}$ & 896 & 1166 \\
\hline b & 1 & 6 & $\mathrm{~b}$ & 7 & 6 \\
\hline $\mathrm{S}$ & 0,998 & 0,998 & S & 0,992 & 0,995 \\
\hline $\mathrm{S}^{\mathrm{L}}$ & 0,927 & 0,927 & $\mathrm{~S}^{\mathrm{L}}$ & 0,736 & 0,826 \\
\hline 1994 & & & 1999 & & \\
\hline $\mathrm{N}$ & 26 & 40 & $\mathrm{~N}$ & 28 & 34 \\
\hline $\mathrm{a}$ & 694 & 1366 & $\mathrm{a}$ & 886 & 1066 \\
\hline b & 4 & 7 & b & 1 & 9 \\
\hline $\mathrm{S}$ & 0,994 & 0,995 & $S$ & 0,998 & 0,992 \\
\hline $\mathrm{S}^{\mathrm{L}}$ & 0,796 & 0,827 & $\mathrm{~S}^{\mathrm{L}}$ & 0,927 & 0,736 \\
\hline 1995 & & & 2000 & & \\
\hline $\mathrm{N}$ & 29 & 20 & $\mathrm{~N}$ & 27 & 18 \\
\hline $\mathrm{a}$ & 853 & 422 & $\mathrm{a}$ & 746 & 338 \\
\hline b & 5 & 8 & $\mathrm{~b}$ & 2 & 7 \\
\hline S & 0,994 & 0,981 & $\mathrm{~S}$ & 0,997 & 0,980 \\
\hline$S^{L}$ & 0,796 & 0,482 & $\mathrm{~S}^{\mathrm{L}}$ & 0,892 & 0,464 \\
\hline
\end{tabular}

Primary data for calculation of individual chick survival in broods with one or two chicks, with the Mayfield method. $N=$ Number of chicks, $a=$ Number of exposure days, $b=$ Number of lost chicks, $S=$ Daily survival, calculated according to Beintema (1996), $S^{L}=$ Hatching offledging success $(L=$ period between hatching and fledging, 38 days; Gomersall (1986)). 
Appendix 4. Primärdata för egenskaper hos häckningstjärnarna. $\mathrm{Nr}=$ tjärn nummer, $\AA \mathrm{r}=$ antal år då tjärnen inventerats, Häck. = procent år med häckning, Stora u. = medelantalet stora ungar per par och år (antal år med data inom parentes), 2 stora u. = medelprocenten ungkullar med två "stora" ungar (antal år med data inom parentes), $\mathrm{Ha}=$ areal, ha, Väg = avstånd till väg i km, Sjö = avstånd till fiskevatten i km, Ö = antal lämpliga häckningsöar, Str. = genomstömmande vatten.

Primary data for breeding tarn characteristics. No. = number of the tarn; $Y r=$ number of years surveyed; Breed . $=$ percentage of years with breeding; Large $y .=$ mean number of large young per pair and year (number of years in parentheses); 2 large $y .=$ mean percentage of broods with two large young (number of years with data in parentheses); Ha = surface area, ha; Road = distance to road, $\mathrm{km}$; Lake = distance to fishing water, $\mathrm{km} ; \mathrm{Isl} .=$ occurrence of appropriate breeding islets; Str. = occurrence of water flowing through.

\begin{tabular}{|c|c|c|c|c|c|c|c|c|c|}
\hline $\begin{array}{l}\mathrm{Nr} \\
\text { No. }\end{array}$ & $\begin{array}{l}\text { År } \\
Y r\end{array}$ & $\begin{array}{l}\text { Häck. } \\
\text { Breed. }\end{array}$ & $\begin{array}{l}\text { Stora u. } \\
\text { Large } y \text {. }\end{array}$ & $\begin{array}{l}2 \text { stora u. } \\
2 \text { large } y \text {. }\end{array}$ & $\begin{array}{l}\mathrm{Ha} \\
\mathrm{Ha}\end{array}$ & $\begin{array}{l}\text { Väg } \\
\text { Road }\end{array}$ & $\begin{array}{l}\text { Sjö } \\
\text { Lake }\end{array}$ & $\begin{array}{l}\text { Ö } \\
\text { Isl. }\end{array}$ & $\begin{array}{l}\text { Str. } \\
\text { Str. }\end{array}$ \\
\hline 1 & 10 & $70 \%$ & 0,57 (7) & $33 \%(3)$ & 1,1 & 1,0 & 0,7 & 1 & 1 \\
\hline 2 & 10 & $100 \%$ & $0,90(10)$ & $29 \%$ (7) & 0,7 & 0,7 & 0,2 & 1 & 0 \\
\hline 3 & 10 & $20 \%$ & $0,00(2)$ & - & 0,2 & 0,2 & 0,5 & 1 & 0 \\
\hline 4 & 10 & $100 \%$ & $1,13(8)$ & $43 \%$ (7) & 2,1 & 1,4 & 0,6 & 1 & 1 \\
\hline 5 & 10 & $90 \%$ & $0,78(9)$ & $17 \%(6)$ & 0,8 & 1,3 & 0,2 & 1 & 1 \\
\hline 6 & 10 & $60 \%$ & $0,50(6)$ & $0 \%(3)$ & 0,3 & 1,3 & 0,5 & 1 & 0 \\
\hline 7 & 10 & $10 \%$ & $1,00(1)$ & $0 \%$ (1) & 0,5 & 1,5 & 0,9 & 1 & 0 \\
\hline 8 & 10 & $40 \%$ & 0,75 (4) & $50 \%(2)$ & 0,4 & 1,8 & 1,3 & 1 & 0 \\
\hline 9 & 10 & $100 \%$ & $0,60(10)$ & $0 \%(6)$ & 0,4 & 1,5 & 1,3 & 1 & 0 \\
\hline 11 & 10 & $20 \%$ & $0,00(2)$ & - & 2,0 & 0,3 & 0,9 & 1 & 0 \\
\hline 12 & 10 & $90 \%$ & 0,89 (9) & $14 \%$ (7) & 0,8 & 0,8 & 0,9 & 1 & 0 \\
\hline 21 & 10 & $100 \%$ & $1,22(9)$ & $50 \%(8)$ & 0,3 & 0,3 & 1,9 & 1 & 1 \\
\hline 23 & 10 & $70 \%$ & 0,71 (7) & $0 \%(5)$ & 1,3 & 0,3 & 1,1 & 1 & 0 \\
\hline 24 & 10 & $80 \%$ & $0,75(8)$ & $20 \%(5)$ & 0,7 & 0,7 & 0,7 & 1 & 0 \\
\hline 25 & 10 & $80 \%$ & $0,71(7)$ & $75 \%$ (4) & 0,7 & 0,5 & 0,4 & 1 & 0 \\
\hline 26 & 10 & $30 \%$ & 0,67 (3) & $100 \%$ & 0,2 & 0,0 & 0,2 & 1 & 0 \\
\hline 27 & 10 & $100 \%$ & $0,56(9)$ & $25 \%(4)$ & 7,2 & 0,3 & 0,0 & 1 & 1 \\
\hline 28 & 10 & $10 \%$ & $0,00(1)$ & - & 0,7 & 0,7 & 0,9 & 1 & 0 \\
\hline 29 & 10 & $80 \%$ & $0,63(8)$ & $0 \%(5)$ & 0,8 & 0,7 & 0,9 & 1 & 0 \\
\hline 30 & 10 & $50 \%$ & $0,60(5)$ & $0 \%(3)$ & 0,7 & 0,6 & 0,3 & 1 & 0 \\
\hline 31 & 10 & $90 \%$ & $0,56(9)$ & $67 \%$ (3) & 0,2 & 0,2 & 0,4 & 1 & 0 \\
\hline 32 & 9 & $89 \%$ & $0,88(8)$ & $75 \%$ (4) & 0,4 & 0,1 & 0,5 & 1 & 0 \\
\hline 33 & 10 & $70 \%$ & 1,17 (6) & $33 \%$ (6) & 1,3 & 0,6 & 0,7 & 1 & 1 \\
\hline 34 & 10 & $70 \%$ & $1,14(7)$ & $33 \%(6)$ & 0,6 & 0,5 & 0,5 & 1 & 1 \\
\hline 36 & 10 & $60 \%$ & $0,83(6)$ & $25 \%(4)$ & 0,5 & 0,5 & 3,1 & 1 & 0 \\
\hline 37 & 8 & $25 \%$ & $0,00(1)$ & - & 0,7 & 0,5 & 4,5 & 0 & 1 \\
\hline 38 & 9 & $78 \%$ & $0,43(7)$ & $0 \%(3)$ & 1,7 & 0,4 & 4,6 & 1 & 0 \\
\hline 40 & 8 & $23 \%$ & 0,00 (1) & $100 \%$ & 0,7 & 0,4 & 4,6 & 1 & 0 \\
\hline 41 & 10 & $60 \%$ & $0,50(6)$ & $0 \%(4)$ & 0,8 & 0,7 & 1,2 & 1 & 0 \\
\hline 43 & 9 & $78 \%$ & $0,43(7)$ & $50 \%(2)$ & 0,6 & 0,8 & 0,9 & 1 & 0 \\
\hline 44 & 9 & $67 \%$ & $0,00(6)$ & - & 0,5 & 0,8 & 0,2 & 1 & 0 \\
\hline 45 & 6 & $17 \%$ & - & $0 \%(1)$ & 2,6 & 0,6 & 0,6 & 1 & 1 \\
\hline 46 & 7 & $43 \%$ & $1,00(3)$ & $50 \%(2)$ & 0,2 & 0,4 & 3,0 & 1 & 0 \\
\hline 47 & 8 & $13 \%$ & $1,00(1)$ & $0 \%(1)$ & 0,6 & 0,2 & 0,2 & 1 & 0 \\
\hline 48 & 8 & $13 \%$ & $0,00(1)$ & - & 0,6 & 0,2 & 0,2 & 1 & 0 \\
\hline 49 & 4 & $75 \%$ & $1,00(2)$ & $0 \%$ (3) & 0,9 & 0,4 & 1,5 & 1 & 1 \\
\hline 50 & 9 & $11 \%$ & - & $0 \%$ (1) & 1,8 & 0,4 & 4,4 & 1 & 1 \\
\hline 51 & 10 & $90 \%$ & $1,11(9)$ & $67 \%(6)$ & 0,3 & 0,2 & 0,4 & 0 & 0 \\
\hline 52 & 10 & $100 \%$ & $0,40(10)$ & $33 \%(3)$ & 0,4 & 0,1 & 0,2 & 0 & 0 \\
\hline 53 & 10 & $90 \%$ & $0,44(9)$ & $100 \%(2)$ & 0,9 & 0,1 & 0,2 & 1 & 0 \\
\hline 54 & 10 & $40 \%$ & 0,25 (4) & $0 \%(1)$ & 0,9 & 0,1 & 1,0 & 0 & 0 \\
\hline 55 & 10 & $90 \%$ & $0,38(8)$ & $0 \%(3)$ & 0,7 & 0,3 & 1,0 & 1 & 1 \\
\hline 56 & 10 & $80 \%$ & $0,75(8)$ & $20 \%(5)$ & 2,3 & 0,6 & 0,2 & 0 & 0 \\
\hline
\end{tabular}


Appendix 4. fortsättning continued

\begin{tabular}{|c|c|c|c|c|c|c|c|c|c|}
\hline $\begin{array}{l}\mathrm{Nr} \\
\text { No. }\end{array}$ & $\begin{array}{l}\AA ̊ \\
Y r\end{array}$ & $\begin{array}{l}\text { Häck. } \\
\text { Breed. }\end{array}$ & $\begin{array}{l}\text { Stora u. } \\
\text { Large y. }\end{array}$ & $\begin{array}{l}2 \text { stora } \mathrm{u} \text {. } \\
2 \text { large } y \text {. }\end{array}$ & $\begin{array}{l}\mathrm{Ha} \\
\mathrm{Ha}\end{array}$ & $\begin{array}{l}\text { Väg } \\
\text { Road }\end{array}$ & $\begin{array}{l}\text { Sjö } \\
\text { Lake }\end{array}$ & $\begin{array}{l}\text { Ö } \\
\text { Isl. }\end{array}$ & $\begin{array}{l}\text { Str } \\
\text { Str. }\end{array}$ \\
\hline 57 & 10 & $90 \%$ & $1,33(9)$ & $71 \%(7)$ & 3,5 & 0,6 & 1,0 & 1 & 0 \\
\hline 58 & 10 & $80 \%$ & 0,17 (6) & $0 \%(2)$ & 4,1 & 0,3 & 0,5 & 1 & 0 \\
\hline 59 & 8 & $50 \%$ & 0,67 (3) & $33 \%(3)$ & 7,0 & 0,6 & 0,5 & 1 & 1 \\
\hline 60 & 10 & $30 \%$ & 0,00 (3) & - & 1,7 & 0,7 & 0,1 & 0 & 0 \\
\hline 61 & 10 & $90 \%$ & $1,22(9)$ & $38 \%(8)$ & 0,5 & 0,4 & 0,2 & 1 & 0 \\
\hline 62 & 10 & $60 \%$ & $0,83(6)$ & $25 \%$ (4) & 0,8 & 0,3 & 0,5 & 1 & 0 \\
\hline 63 & 8 & $25 \%$ & $2,00(2)$ & $100 \%(2)$ & 0,7 & 0,1 & 0,9 & 0 & 0 \\
\hline 65 & 7 & $100 \%$ & $0,83(6)$ & $20 \%(5)$ & 2,9 & 0,5 & 1,0 & 1 & 1 \\
\hline 66 & 7 & $71 \%$ & $1,00(5)$ & $0 \%(5)$ & 0,4 & 0,3 & 0,5 & 0 & 0 \\
\hline 67 & 7 & $71 \%$ & $1,25(4)$ & $50 \%(4)$ & 1,1 & 1,3 & 1,4 & 1 & 1 \\
\hline 68 & 7 & $86 \%$ & 1,17 (6) & $75 \%$ (4) & 0,4 & 0,5 & 0,6 & 1 & 0 \\
\hline 69 & 4 & $50 \%$ & $1,00(1)$ & $50 \%(2)$ & 0,3 & 0,9 & 0,0 & 1 & 0 \\
\hline 70 & 9 & $33 \%$ & 0,67 (3) & $0 \%(2)$ & 1,4 & 0,9 & 1,0 & 1 & 1 \\
\hline 72 & 9 & $100 \%$ & $1,13(8)$ & $25 \%(8)$ & 0,9 & 0,6 & 1,0 & 1 & 1 \\
\hline 73 & 10 & $30 \%$ & $0,50(2)$ & $0 \%(1)$ & 0,9 & 0,2 & 0,2 & 1 & 0 \\
\hline 74 & 10 & $80 \%$ & $1,25(8)$ & $67 \%(6)$ & 0,4 & 0,1 & 0,1 & 1 & 1 \\
\hline 75 & 10 & $20 \%$ & $1,00(2)$ & $100 \%$ (1) & 2,0 & 0,1 & 0,7 & 1 & 0 \\
\hline 76 & 9 & $22 \%$ & 0,00 (1) & $0 \%(1)$ & 5,0 & 0,1 & 0,5 & 1 & 0 \\
\hline 77 & 5 & $80 \%$ & $1,00(3)$ & $0 \%(4)$ & 1,6 & 0,7 & 1,7 & 1 & 1 \\
\hline 78 & 3 & $67 \%$ & $1,50(2)$ & $50 \%(2)$ & 1,9 & 0,2 & 0,3 & 1 & 1 \\
\hline 79 & 10 & $10 \%$ & 1,00 (1) & $0 \%(1)$ & 0,1 & 0,2 & 3,4 & 1 & 0 \\
\hline 80 & 10 & $20 \%$ & $1,00(2)$ & $100 \%$ (1) & 0,2 & 0,2 & 0,3 & 1 & 0 \\
\hline 81 & 10 & $70 \%$ & $0,71(7)$ & $25 \%$ & 0,3 & 0,2 & 0,2 & 1 & 0 \\
\hline 82 & 10 & $90 \%$ & $1,00(9)$ & $29 \%$ (7) & 0,3 & 0,3 & 0,1 & 1 & 0 \\
\hline 83 & 10 & $30 \%$ & 0,00 (3) & - & 0,5 & 0,5 & 0,2 & 0 & 0 \\
\hline 84 & 9 & $78 \%$ & $0,83(6)$ & $50 \%$ (4) & 0,2 & 0,9 & 0,0 & 1 & 0 \\
\hline 85 & 9 & $67 \%$ & $1,20(5)$ & $100 \%$ (4) & 1,2 & 1,1 & 0,7 & 1 & 0 \\
\hline 86 & 10 & $10 \%$ & & $0 \%(1)$ & 8,5 & 0,7 & 0,7 & 1 & 0 \\
\hline 87 & 10 & $70 \%$ & $0,57(7)$ & $33 \%(3)$ & 0,5 & 1,6 & 0,6 & 1 & 0 \\
\hline 88 & 10 & $70 \%$ & 0,67 (6) & $0 \%$ (4) & 0,7 & 0,5 & 0,6 & 1 & 0 \\
\hline 89 & 10 & $70 \%$ & $1,33(6)$ & $50 \%(6)$ & 1,4 & 0,1 & 0,7 & 1 & 0 \\
\hline 90 & 10 & $10 \%$ & $1,00(1)$ & $0 \%(1)$ & 1,6 & 0,3 & 0,6 & 1 & 0 \\
\hline 91 & 10 & $90 \%$ & 0,67 (9) & $20 \%(5)$ & 1,4 & 0,1 & 0,1 & 1 & 0 \\
\hline 92 & 10 & $90 \%$ & $0,71(7)$ & $33 \%(6)$ & 1,4 & 0,2 & 0,3 & 1 & 0 \\
\hline 93 & 10 & $90 \%$ & $0,56(9)$ & $0 \%(5)$ & 0,3 & 1,1 & 1,2 & 1 & 0 \\
\hline 95 & 10 & $50 \%$ & $0,00(5)$ & - & 1,3 & 0,4 & 0,5 & 0 & 0 \\
\hline 96 & 9 & $100 \%$ & $0,67(9)$ & $20 \%(5)$ & 0,5 & 0,1 & 2,5 & 1 & 0 \\
\hline 97 & 9 & $89 \%$ & 0,57 (7) & $33 \%(3)$ & 1,3 & 0,2 & 2,2 & 1 & 0 \\
\hline 98 & 7 & $14 \%$ & - & $0 \%(1)$ & 1,6 & 0,6 & 1,8 & 1 & 0 \\
\hline 99 & 10 & $100 \%$ & $1,20(10)$ & $33 \%(9)$ & 0,6 & 1,0 & 0,1 & 1 & 0 \\
\hline 100 & 9 & $100 \%$ & $1,13(7)$ & $50 \%(6)$ & 3,0 & 0,2 & 1,0 & 1 & 0 \\
\hline 101 & 10 & $60 \%$ & $0,33(6)$ & $0 \%(2)$ & 0,7 & 0,3 & 1,5 & 1 & 0 \\
\hline 102 & 10 & $30 \%$ & $1,00(3)$ & $50 \%(2)$ & 2,3 & 0,0 & 1,8 & 1 & 1 \\
\hline 103 & 10 & $30 \%$ & $1,00(3)$ & $50 \%(2)$ & 1,0 & 1,0 & 2,3 & 1 & 0 \\
\hline 104 & 7 & $57 \%$ & $0,25(4)$ & $0 \%(1)$ & 0,8 & 0,4 & 0,7 & 1 & 0 \\
\hline 105 & 9 & $67 \%$ & 0,67 (6) & $33 \%(3)$ & 0,6 & 1,3 & 0,4 & 1 & 0 \\
\hline 106 & 5 & $60 \%$ & $0,00(3)$ & - & 6,9 & 0,1 & 0,2 & 1 & 1 \\
\hline 107 & 5 & $80 \%$ & $0,75(4)$ & $0 \%(3)$ & 0,4 & 0,4 & 1,5 & 1 & 0 \\
\hline 108 & 5 & $80 \%$ & $0,50(4)$ & $0 \%(2)$ & 1,9 & 0,3 & 0,1 & 1 & 0 \\
\hline 109 & 10 & $10 \%$ & 0,00 (1) & - & 0,2 & 0,1 & 0,9 & 1 & 0 \\
\hline 110 & 5 & $60 \%$ & $0,33(3)$ & $0 \%$ & 0,8 & 0,5 & 1,3 & 0 & 0 \\
\hline 111 & 2 & $100 \%$ & 0,00 (1) & $0 \%(1)$ & 1,3 & 0,4 & 3,4 & 1 & 1 \\
\hline
\end{tabular}


Appendix 5. Primärdata för fiskesjöar. Koordinater enligt Rikets nät. Avstånd är medelavståndet till samtliga tjärnar från vilka lommarna fiskar i respektive sjö, "Stora" ungar är medelantal "stora" ungar per häckande par, \% med 2 "stora" är medelandelen kullar med två "stora" ungar.

Primary data for fishing lakes. Co-ordinates according to the Swedish national grid. Distance is the mean distance to all tarns from which the divers fish in each lake, "Large" young is the mean number of "large" young per breeding pair, \% with 2 "large" is the mean percentage of broods with two "large" young.

$\begin{array}{llllllllllll}\text { Sjö, koordinater, distance } & 1991 & 1992 & 1993 & 1994 & 1995 & 1996 & 1997 & 1998 & 1999 & 2000 & \text { Medel }\end{array}$

Lake; co-ordinates, distance

Mean

\section{Bredsjön}

(668028; 139334); 0,8 km ( $\mathrm{n}=11)$

Undersökta tjärnar Surveyed tarns

Med häckning With breeding

$\%$ med häckning \% with breeding

"Stora" ungar "Large" young

Antal par No. of pairs

$\%$ with 2 "stora" \% with 2 "large"

Antal par No. of pairs

\begin{tabular}{rrrrrrrrrrr}
11 & 11 & 11 & 11 & 11 & 11 & 11 & 11 & 11 & 11 & \\
5 & 6 & 8 & 9 & 8 & 8 & 6 & 7 & 8 & 4 & \\
45 & 55 & 73 & 82 & 73 & 73 & 55 & 74 & 73 & 36 & 64 \\
0,60 & 1,33 & 0,38 & 0,78 & 0,88 & 0,63 & 0,50 & 1,00 & 0,75 & 0,50 & 0,74 \\
5 & 6 & 8 & 9 & 8 & 8 & 6 & 6 & 8 & 4 & \\
50 & 60 & 0 & 17 & 0 & 25 & 0 & 17 & 50 & 0 & 22 \\
2 & 5 & 3 & 6 & 7 & 4 & 1 & 6 & 4 & 2 & \\
\hline
\end{tabular}

\section{Holmsjön-Kappsjösystemet}

(671301; 138338); 0,6 km ( $\mathrm{n}=15)$

Undersökta tjärnar Surveyed tarns

Med häckning With breeding

$\%$ med häckning $\%$ with breeding

"Stora" ungar "Large" young

Antal par No. of pairs

$\%$ with 2 "stora" \% with 2 "large"

Antal par No. of pairs

\begin{tabular}{rrrrrrrrrrr}
9 & 11 & 11 & 13 & 14 & 15 & 14 & 15 & 14 & 15 & \\
8 & 8 & 7 & 10 & 9 & 11 & 8 & 10 & 11 & 8 & \\
89 & 73 & 64 & 77 & 64 & 73 & 57 & 67 & 79 & 53 & 70 \\
1,17 & 0,83 & 0,86 & 0,78 & 1,11 & 0,36 & 0,57 & 0,70 & 0,73 & 0,88 & 0,80 \\
6 & 6 & 7 & 9 & 9 & 11 & 7 & 10 & 11 & 8 & \\
43 & 67 & 50 & 33 & 43 & 33 & 100 & 40 & 60 & 17 & 47 \\
7 & 3 & 4 & 6 & 7 & 3 & 3 & 5 & 5 & 6 & \\
\hline
\end{tabular}

\section{Kvien}

(669437; 138966); 1,6 (n=19)

Undersökta tjärnar Surveyed tarns

Med häckning With breeding

$\%$ med häckning \% with breeding

"Stora" ungar "Large" young

Antal par No. of pairs

$\%$ with 2 "stora" \% with 2 "large"

Antal par No. of pairs

\begin{tabular}{rrrrrrrrrrr}
12 & 16 & 18 & 19 & 19 & 19 & 18 & 17 & 17 & 18 & \\
8 & 9 & 10 & 10 & 8 & 12 & 10 & 11 & 9 & 5 & \\
67 & 56 & 56 & 53 & 42 & 63 & 56 & 65 & 53 & 28 & 54 \\
0,20 & 1,00 & 1,10 & 0,90 & 0,25 & 0,50 & 0,50 & 0,27 & 0,67 & 0,75 & 0,64 \\
5 & 8 & 10 & 10 & 8 & 12 & 10 & 11 & 9 & 4 & \\
50 & 33 & 83 & 80 & 0 & 20 & 33 & 50 & 0 & 0 & 35 \\
4 & 6 & 6 & 5 & 2 & 5 & 6 & 2 & 6 & 4 & \\
\hline
\end{tabular}

\section{Petsjön}

(672639; 136883); 0,7 km ( $\mathrm{n}=5)$

Undersökta tjärnar Surveyed tarns

Med häckning With breeding

$\%$ med häckning $\%$ with breeding

"Stora" ungar "Large" young

Antal par No. of pairs

$\%$ with 2 "stora" \% with 2 "large"

Antal par No. of pairs

\begin{tabular}{rrrrrrrrrrr}
4 & 4 & 4 & 4 & 4 & 4 & 5 & 5 & 5 & 5 & \\
1 & 4 & 2 & 3 & 2 & 2 & 3 & 3 & 3 & 3 & \\
25 & 100 & 50 & 75 & 50 & 50 & 60 & 60 & 60 & 60 & 59 \\
1,00 & 2,00 & 2,00 & 0,33 & 0,50 & 1,50 & 2,00 & 1,00 & 0,67 & 0,67 & 1,17 \\
1 & 2 & 2 & 3 & 2 & 2 & 2 & 3 & 3 & 3 & \\
0 & 67 & 100 & 0 & 0 & 50 & 67 & 0 & 0 & 0 & 28 \\
1 & 3 & 2 & 1 & 1 & 2 & 3 & 3 & 2 & 2 & \\
\hline
\end{tabular}

\section{Rönnhällssjön - Nyckelhällsjön}

(673649;136631); 0,4 km ( $=11)$

Undersökta tjärnar Surveyed tarns

Med häckning With breeding

$\%$ med häckning \% with breeding

"Stora" ungar "Large" young

Antal par No. of pairs

$\%$ with 2 "stora" \% with 2 "large"

Antal par No. of pairs

$\begin{array}{rrrrrrrrrrr}9 & 11 & 11 & 11 & 11 & 11 & 11 & 11 & 11 & 11 & \\ 4 & 6 & 6 & 7 & 4 & 4 & 6 & 3 & 6 & 5 & \\ 44 & 55 & 55 & 64 & 36 & 36 & 55 & 27 & 55 & 45 & 47 \\ 1,00 & 1,67 & 1,17 & 1,29 & 0,25 & 1,25 & 0,33 & 0,67 & 0,17 & 0,40 & 0,82 \\ 3 & 3 & 6 & 7 & 4 & 4 & 6 & 3 & 6 & 5 & \\ 33 & 60 & 40 & 50 & 0 & 25 & 0 & 100 & 0 & 0 & 31 \\ 3 & 5 & 5 & 6 & 1 & 4 & 2 & 1 & 1 & 2 & \end{array}$


Appendix 5, fortsättning continued

\begin{tabular}{|c|c|c|c|c|c|c|c|c|c|c|c|}
\hline $\begin{array}{l}\text { Sjö, koordinater, distance } \\
\text { Lake; co-ordinates, distance }\end{array}$ & 1991 & 1992 & 1993 & 1994 & 1995 & 1996 & 1997 & 1998 & 1999 & 2000 & $\begin{array}{l}\text { Medel } \\
\text { Mean }\end{array}$ \\
\hline $\begin{array}{l}\text { Öjen } \\
(674350 ; 139682 ; 1,2 \text { km (n=20 }\end{array}$ & & & & & & & & & & & \\
\hline Undersökta tjärnar Surveyed tarns & 9 & 14 & 14 & 15 & 15 & 19 & 19 & 18 & 20 & 19 & \\
\hline Med häckning With breeding & 5 & 7 & 9 & 11 & 11 & 10 & 14 & 15 & 16 & 10 & \\
\hline$\%$ med häckning $\%$ with breeding & 56 & 50 & 64 & 73 & 73 & 53 & 74 & 83 & 80 & 53 & 66 \\
\hline "Stora" ungar "Large" young & 0,75 & 1,00 & 1,25 & 0,64 & 0,45 & 0,20 & 0,36 & 1,07 & 0,69 & 0,25 & 0,56 \\
\hline Antal par No. of pairs & 4 & 5 & 8 & 11 & 11 & 10 & 14 & 14 & 16 & 8 & \\
\hline$\%$ with 2 "stora" $\%$ with 2 "large" & 33 & 25 & 57 & 17 & 0 & 0 & 0 & 55 & 10 & 0 & 20 \\
\hline Antal par No. of pairs & 3 & 4 & 7 & 6 & 5 & 2 & 5 & 11 & 10 & 4 & \\
\hline
\end{tabular}

